\title{
Politicians, the Media, and Domestic Audience Costs
}

\author{
Branislav L. Slantchev* \\ Department of Political Science, University of California - San Diego
}

September 6, 2005

\begin{abstract}
Domestic audience costs can help leaders establish credible commitments by tying their hands. Most studies assume these costs without explaining how they arise. I link domestic audience costs to the citizens' ability to sanction the leadership for pursuing policies they would not want if they had the same information about their quality. How can citizens learn about policy quality? I model two information transmission mechanisms: one potentially contaminated by politically-motivated strategic behavior (leader and opposition), and another that is noisy and possibly biased (media). In equilibrium, audience costs can arise from strategic sources only in mixed regimes under relatively restrictive conditions, and cannot arise in autocracies or democracies. However, in democratic polities the media can play a mitigating role and does enable leaders to generate audience costs. Still, their ability to do so depends on the institutional protections guaranteeing freedom of the media from political manipulation. Domestic audience costs are not necessarily linear in regime type, as often assumed in applied research.
\end{abstract}

\footnotetext{
*Email: slantchev@ucsd.edu. First, I thank Hein Goemans without whom this paper would not have existed. I also thank Robert Powell, Allan Stam, Jessica Weiss, Robert Walker, Matthew Baum, Jeffrey Lax, Ernesto Dal Bo, Benjamin Valentino, Kristian Gleditsch, and William Wohlforth for insightful discussions. I am grateful to the participants of the Positive Political Theory seminar at the University of California, Berkeley, and the IR Working Group at Dartmouth College for helpful comments. I gratefully acknowledge financial support from the National Science Foundation (Grant SES-0518222).
} 


\section{Introduction}

Tying hands can be an effective way to communicate the credibility of one's commitment (Schelling 1966). Domestic audience costs are one mechanism for doing so that has become fairly popular in recent studies of international behavior (Fearon 1994a). Briefly, if leaders take actions that increase the costs of backing down from their position, then they can effectively commit to holding out for concessions. However, as Smith (1998) and Schultz (1999) note, this mechanism lacks microfoundations: the theoretical models that investigate the impact of audience costs on behavior have largely taken them for granted. This article clarifies what an interpretation of domestic audience costs would look like, and investigates the theoretical possibility for generating such costs endogenously. Under what conditions would a rational audience impose such costs on a leader? How do these conditions depend on the institutional structure of the polity?

The results suggest that while it is possible for these costs to arise, their generation is far from straightforward. In particular, if one relies solely on strategic sources of information (government, opposition parties), citizens of either democracies or autocracies are unlikely to learn enough to credibly threaten to sanction their leaders for bad behavior. Even though the reasons for such failure differ between the two regime types, the consequences are similar. This suggests that the widespread identification of regime type with audience costs may be seriously misleading, with attendant consequences for empirical studies. For example, it would not be correct to say that a democracy would necessarily signal better than an autocracy because of audience costs.

On the other hand, I find a somewhat mitigating factor that might recover some of the democratic polity's ability to learn more than its autocratic counterpart. A non-political (exogenous) source of information, such as a free press, could have a serious impact even if the signal it sends is noisy and potentially biased. While citizens of a democracy can impose costs on their leaders only imperfectly, they could still do so provided the alternative sources of information are not highly politically manipulable. This implies that democracies themselves can be ranked with respect to their ability to generate audience costs: The ones with more media protections would enable their citizens to sanction leaders much better.

Taken together, these findings suggest that we should pay closer attention to the causal mechanism from which audience costs are supposed to arise and most certainly should not take them for granted as an assumption in our models. While much of the emphasis has been on the strategic sources of information, perhaps we should investigate in much more depth the interaction between government, opposition parties, and media in the public forum with domestic audiences. As Miller and Krosnick (2000) have shown, citizens infer the importance of an issue from the extent of its media coverage, making media accuracy and credibility significant factors in that process.

\section{The Puzzle of Endogenous Audience Costs}

Domestic audience costs play an increasingly important role in theoretical and empirical work in international relations. For example, audience cost arguments have been used to build theories about debt repayment (Schultz and Weingast 2003), peaceful conflict resolution (Lipson 2003, Ch. 1), alliance reliability (Gaubatz 1996), economic sanctions 
(Dorussen and Mo 2001), trade agreement compliance (Mansfield, Milner and Rosendorff 2002), international cooperation (Leeds 1999), and monetary credibility (Lohmann 2003). ${ }^{1}$ On the empirical front, we have studies of the supposed effects of audience costs on alliances (Gaubatz 1996), crisis escalation (Eyerman and Hart, Jr. 1996), and militarized dispute outcomes (Palmer and Partell 1999), as well as studies of the supposed variation of audience costs across regime types (Gowa 2001). ${ }^{2}$ Although these studies take the existence of these costs and their linearity in regime type (democracies have higher costs) as unproblematic, this is not so. Indeed, with the notable exception of Smith (1998), the theoretical microfoundations of the process that is supposed to generate these costs have not even been analyzed. This means that at stake are theoretical studies that build upon models that assume such costs and empirical studies that evaluate hypotheses derived from such models. Although the following discussion is framed in terms of crisis bargaining, the argument is much more general.

\subsection{Credibility in Crisis Bargaining}

The resolution of conflict in many international situations turns on the ability of actors to commit credibly to some course of action. In a crisis, the opponent would pay attention to a threat to resort to arms only if it is credible; an alliance would have a deterrent effect only if the defender's promise to come to the aid of his protégé is credible; and so on.

Under asymmetric information, communicating commitments is fraught with difficulty. The actor with a genuine threat must somehow separate himself from the plethora of possible threateners who are mere bluffers. One possibility is to engage in an action that would not be in the interest of a bluffer to carry out: Doing so should provide convincing proof of one's intentions. But what would such an action be? In a crisis, the negotiated outcome turns on the difference between the expected payoffs from war and peace: an actor has to concede more to an opponent who believes he would do well fighting than to an opponent who believes himself too weak to fight. An actor with a high expected payoff from war relative to peace could demand a large concession because he would have to be compensated for not fighting.

The goal, then, is to persuade the opponent either that one's expected payoff from war is relatively high, or that one's expected payoff from peace is relatively low. With the exception of nuclear crises, one can envision circumstances where deliberate attack is a rational decision. If one succeeds in making the expected value of war better than the expected value of peace, one has effectively established a genuine threat to attack should the circumstances ever arise.

This implies that actors would engage in behavior that is designed to alter the strategic environment such that war becomes optimal if the opponent fails to concede enough. One

\footnotetext{
${ }^{1}$ Lohmann's (2003) argument that fiat monetary institutions are credible is an exception because there is at least some incentive to trigger the imposition of costs. When a government dollarizes the economy, it "creates an audience for devaluation or an exit from the fixed-exchange regime," and it is this audience that has a monetary interest in punishing reversals.

${ }^{2}$ Gowa (2001) has doubts about the unstated assumptions about the electoral process that underlie audience costs models and only tentatively adopts them as a plausible working hypothesis. See Schultz (2001b) for the difficulties involved with empirical tests of audience costs arguments in general.
} 
straightforward way of doing that is through actions that decrease the value of peace obtained by one's own backing down: if peace is less palatable, the one is less likely to opt for it. Fearon (1994a) postulates just such a mechanism for tying one's hands: a leader who escalates a crisis also increases his domestic audience costs, which he has to pay if he backs down. Since escalating further may get the opponent to concede, leaders would be tempted to do just that in order to avoid paying these costs. The more a leader escalates, the higher the costs of backing down, and the more credible the threat not to quit. If both leaders escalate too far, they can become locked in a position from which neither one would recede, thereby ensuring war. In a way, the cure (costly signaling through audience costs) can be worse than the disease (inability to signal resolve).

Through their tying hands effect, audience costs can influence crisis behavior in a fairly well-understood way, which probably accounts for the popularity of this commitment mechanism in recent studies. There is no question that if leaders can generate such costs, then they would be able to derive bargaining advantage from them under some conditions. ${ }^{3}$ However, this is a big "if."

\subsection{Foreign Policy Agency and Citizen Control}

In the original article, Fearon (1994a) assumes that citizens punish leaders who bluff by escalating a crisis and then back down; hence escalation involves increasing audience costs. He assumes that audience costs exist and justifies this assumption with an appeal to national honor; that is, citizens punish the leader for failing to uphold it. As others have noted, however, it is unclear why citizens should punish their leaders for getting caught in a bluff when bluffing may be an optimal strategy (Schultz 1999), or when they may be happy that the leader avoided a costly foreign entanglement (Smith 1998). Without microfoundations, the domestic audience cost story sounds a lot less persuasive. ${ }^{4}$

Why would a leader incur audience costs by escalating a crisis and then backing down? Why would audience costs increase with the level of escalation? Fearon (1994a, p. 581) offers the following justification for the suggested norm of punishing more severely a leader who concedes after escalation than one who concedes outright: Because ability to commit in a crisis may be so beneficial, "if the principal [citizens] could design a 'wage contract' for the foreign policy agent [leader], the principal would want to commit to punishing the agent for escalating a crisis and then backing down... principals who conduct foreign policy themselves may not be able credibly to commit to self-imposed punishment (such as leaving power) for backing down in a crisis." In other words, because it would benefit the leader to tie his hands through audience costs, citizens will want to impose them. This may be so, but it does not mean that the citizens will actually be able to credibly commit to such a strategy. Regardless of how much they would like to do it, if they do not have the incentives to carry out the punishment, the threat becomes incredible, and audience costs disappear. Wishing a commitment does not make it credible. If it did, the leader could analogously threaten to remove himself from office, and it would work just as well.

\footnotetext{
${ }^{3}$ Baum (2004) studies when leaders might prefer to make their demands in private and forego public commitments if the latter generate audience costs. For summaries and empirical evaluations of citizen rationality, see Shapiro and Page (1988) and Knopf (1998).

${ }^{4}$ Audience costs can be imposed by foreign actors (Sartori 2002). The focus here is on domestic sources.
} 
Because the leader cannot very well promise to just step aside, it must be the case that if audience costs are to arise, the audience must credibly commit to punishing the leader. This means that we have to figure out exactly how it can do that. As we shall see, producing such a commitment requires either divergent preferences over foreign policy goals or asymmetric information about the policy itself along with incentives to distort such knowledge.

To see this, suppose that both the leader and the citizens value national honor and that they care equally how well the country will do in the crisis. That is, assume that principal and agent have aligned preferences. This now implies that the two actors are essentially interchangeable: the leader would not do anything the citizens do not want him to do or would not do themselves if they were in his shoes. The leader would not want to run risks higher than citizens would, and he would not bluff in situations that citizens would not. Even if the principal is asymmetrically informed, it would not distort the agent's incentives.

This is a general result from the analysis of moral hazard problem which arises in any principal-agent relationship where (1) the principal cannot observe the agent's action, (2) the outcome is only an imperfect signal of the action, and (3) the agent and the principal have conflicting interests. As Laffont and Martimort (2002, p. 146) put it, "moral hazard would not be an issue if the principal and the agent had the same objective function. Crucial to the agency cost arising under moral hazard is the conflict between the principal and the agent over which action should be carried out." Furthermore, the problem only arises when the relationship between the agent's unobservable action and its observable result is noisy: that is, actions do not neatly map into outcomes. If they did, then the principal could infer the agent's action as easily as observing it directly, and could base the threat on the result rather than on the agent's behavior.

What do these results imply for our discussion? If the leader and the citizens have the same preferences over foreign policy and national honor, then whatever the leader does will be perfectly aligned with the interests of the citizens, and hence it is not credible for them to threaten punishment even if the policy fails. Citizens would dearly love to be able to impose audience costs on the leader but in this situation there is no conceivable rational reason to do so. Because of this, the foreign actor would not lend citizen opinion any more credence than she is prepared to bestow upon the leader.

We conclude that domestic audience costs can arise only if for some reason the leader is (tempted to be) an unfaithful agent. There are at least two ways this can happen. One is that the leader simply has different foreign policy goals from his constituency. For example, he may care about the disputed issue much more deeply than the average citizen, which could lead him to risk more to achieve his goals. However, this introduces an even larger problem for audience cost arguments. Whereas it is true that the public would want to deter the leader from leaping into unwanted foreign adventures-and hence opposition would increase with escalation, it does not follow that audience costs must increase with escalation too or that they would be useful as a signaling device.

To see that, observe that if the audience is to be able to impose costs for backing down after escalating, its estimate of the reputational loss must exceed the leader's. Otherwise, the leader would have backed down much sooner because he would have wanted to avoid having to suffer this loss which he values so highly. The only way to avoid the problem is to assume that citizens care more about foreign policy than the leader does. This would certainly help lend credibility to the threat to punish backing down but appears to be a heroic 
assumption that will rarely be satisfied in practice.

This is not to say that it cannot happen. For example, the recent bout of public nationalist anti-Japanese demonstrations in China could be viewed as an attempt by the Chinese government to generate audience costs and compel Japan to be more forthcoming with her apology, and even perhaps reconsider any actions (such as candidacy to the UNSC) that might displease China. In effect, the communist government was threatening with a public that is much more hawkish in that respect than itself: if things got "out of control," the Chinese government could be compelled to demand much more of Japan than it otherwise would. Of course, if I were the Japanese Prime Minister, I would very much doubt that the Chinese government could risk letting things get out of control or even allowing the demonstrations to continue much longer: after all, any organized protest provides experience to the masses that could later be turned on the communist government itself. ${ }^{5}$

Hence, whereas it is possible to imagine circumstances where more hawkish domestic political audiences could generate the appropriate costs, it is doubtful that these situations are empirically common. In fact, what we usually associate with public opinion during a crisis involves opposition to the escalation of the crisis or the use of force, not agitation for a more hard-line policy or clamoring for war. If this is the case, then the public is much more likely to punish the leader for escalating and going to war even if it does not reward him for backing down and preserving the peace. Such domestic audiences not only fail to tie the leader's hands but actually make his threats to escalate much less credible. ${ }^{6}$

Therefore, even if the leader cares more about foreign policy than the public does, domestic audience costs cannot arise unless the public actually cares more than the leader about the consequences for backing down after escalation. This implies that we have to look for the audience cost generating mechanism in the other way the moral hazard problem can arise. Namely, the case where the agent's action could potentially reveal some information to the principal that would be detrimental to the agent's interests. The one sanction that domestic audiences can impose on the leader is to remove him from office. If escalating and backing down causes the audience to revise downward its estimate of the desirability of keeping the leader, then it can rationally threaten to remove him, which in turn would generate the appropriate audience costs. ${ }^{7}$

Fundamentally, audience costs are supposed to "arise from the action of domestic political audiences concerned with whether the leadership is successful or unsuccessful at foreign policy" (Fearon 1994b, p. 241). Why would citizens punish their leader? Presumably, the only circumstance where they would be willing to do it is when they find out that his behavior was different from what they would have done if they had the same information (Downs and Rocke 1995). That is, citizens do not punish for honest mistakes but would like to

\footnotetext{
${ }^{5}$ I thank Jessica Weiss for suggesting this example and the audience cost interpretation.

${ }^{6}$ Examples of this abound, the most recent one being the Bush administration's threat to invade Iraq. Given the significant domestic opposition to the use of force (along with the dithering or outright hostility of American allies), one has to wonder just how much Saddam Hussein believed the threat during the crisis. Add to that the decade-long American preference for sanctions-which could be seen as a substitute for war-and the risky Iraqi policy in late 2002 and early 2003 becomes very intelligible indeed.

${ }^{7}$ Note, however, that the original argument still requires that citizens become even more hostile to the leader the longer he escalates. That is, the higher the level of escalation preceding the backing down, the less desirable such a leader.
} 
punish deliberate malfeasance. What matters is not whether citizens like the outcomes or not, but whether they would have wanted the policy if they knew all that the leader knows. In other words, leaders are judged on how faithful agents they are of the citizenry who acts as the principal.

When we ask the question in this way, it becomes immediately clear that the idea of audience costs is closely related to the question of citizen control. ${ }^{8}$ Domestic audience costs arguments are essentially about informational asymmetries and the ability of citizens to sanction their government for "inappropriate" behavior. Domestic audience costs are the direct reduction in the leader's reselection probability that occurs in equilibrium because of citizens inferring information unfavorable to the incumbent. That is, instead of assuming audience costs, we want to obtain them as consequence of equilibrium behavior; we want them to arise endogenously.

Smith (1998) was the first to suggest such an approach to audience costs. To answer why citizens would want to remove leaders who renege on their foreign policy commitments, he presents a moral hazard model where leaders are asymmetrically informed about their competence and foreign policy outcomes serve as noisy signals about it. Because more competent leaders perform better, only leaders who expect a poor outcome will avoid following through on their commitments. Such an action signals to citizens that the leader is incompetent, which in turns makes their threat to replace him credible.

There are at least two reasons to seek alternative theoretical microfoundations for audience costs. First, in the informative equilibrium in Smith (1998), more competent leaders make threats and then carry them out if they have to whereas less competent leaders do not make any threats. Domestic audience costs, however, are only incurred if a leader makes a threat but then fails to follow through. This means that audience costs are only imposed off the equilibrium path because in equilibrium no leader who expects to back down ever makes a threat in the first place. This now means that citizen beliefs about leader's competence are not pinned down by equilibrium behavior but are imposed exogenously. Smith (1998, pp. 631, 635) assumes that if a leader backs down after a threat, citizens conclude that he is the least competent type. Whereas this naturally provides the strongest disincentive for reneging on commitments, it is assumed rather than derived from equilibrium behavior. All this implies that audience costs occur by fiat in this model. Note also that in Fearon's (1994a) model, leaders incur audience costs in equilibrium and indeed there is no other way to make the escalatory logic work. This further implies that a justification for audience costs that never involves such costs in equilibrium is perhaps inadequate.

Second, by assuming that leaders are severely penalized for backing down, Smith (1998) implicitly assumes that bluffing can never be the optimal course for leaders during a crisis. As I argued before, such a thing is by no means clear. In fact, in Fearon's (1994a) model, bluffing always occurs with strictly positive probability as leaders balance the risk of lockin they run by escalation against the gains from the probability of the opponent conceding if they escalate slightly more. If bluffing is optimal, there is no reason for citizens to punish it. Indeed, both backing down and standing firm are observables that are consistent with the same strategy, which implies that citizens can hardly use them to infer much about the

\footnotetext{
${ }^{8}$ For models of elections, see Ferejohn (1986), Alesina, Londregan and Rosenthal (1993), and Smith $(1996 b)$.
} 
strategy's quality. Hence, because one should not expect to see such a disincentive and because the existing disincentive is assumed, we must look for an alternative explanation.

\subsection{Where Do Citizens Learn From?}

We have now arrived at the connection between foreign policy, government selection, information available to the citizens, and audience costs. We have concluded that if audience costs are to be useful as signaling devices, the foreign actor must believe that the citizens would punish the leader for escalating and backing down. She will do so only if this threat is credible, and it can only be credible if it can be sustained in equilibrium. This, in turn, is only possible if the leader and the citizens have divergent preferences, are asymmetrically informed, and if outcomes are only imperfectly correlated with the leader's actions. Because delegation under asymmetric information and divergent preferences involves agency costs, "the principal is interested in any signals that reveal new information on the agent's effort" (Macho-Stadler and Pérez-Castrillo 1997, p. 55). Consequently, I now turn to examining such potential sources of information.

Clearly, the actions of the leader are the most immediate source of information. However, strategic leaders are aware that their every move would be closely scrutinized for any clues about policy quality, and hence their behavior will take that into account. That is, we should expect leaders to engage in strategic deception, which means that they cannot be relied upon to provide the (potentially detrimental) information citizens need to evaluate their performance.

I will consider two additional potential sources of information: a political opposition and a non-office-seeking source, such as the media. The first source may be "contaminated" by the opposition's desire to gain office, and the second source may be "noisy" in that there is a chance that it would misreport a good policy as bad and vice versa.

Schultz (1998) shows that an opposition could buttress the leader's signaling even in the absence of domestic audience costs. This transfers the signaling burden onto the political system and the presence of alternative sources of information. If the opposition could credibly reveal unfavorable information, it could enable citizens to make the necessary inferences and impose costs on the leader for pursuing a bad policy. Because Schultz focuses on the opposition's ability to reveal the government's resolve, he does not investigate the effect of the opposition's actions on the citizens. Schultz assumes that citizens are not entirely strategic but behave according to a simple retrospective evaluation framework that apportions blame or credit to the government and the opposition depending on policy outcomes. In other words, the mechanism that is crucial from our perspective is again relegated to an assumption, even though it is a much more plausible one.

I do not assume that the government and the opposition can share credit or blame for existing policy or that the opposition can discipline itself through two-dimensional preferences (as Ramsay (2004) does). Instead, the opposition is just like the leader in that it is first and foremost office-seeking, and, given that, prefers good policies to bad ones, just like the rest of the citizens. ${ }^{9}$ The only potentially disciplining device is at the leader's disposal:

\footnotetext{
${ }^{9}$ There are many assumptions one could make about the opposition that would immediately lead to truthtelling equilibrium behavior. For example, if a statement created a commitment from which would be costly to reverse, or if citizens punished the opposition for incorrect predictions, the opposition would have less incentive
} 
the possibility to repress the opposition if it dissents. Hence, the opposition is free to make any statement but since the leader can repress it, dissent may carry risks.

The other source of information is not office-seeking, and I have in mind something like the media although it could be individual whistle-blowers like Deep Throat or a group of disgruntled people, like Russian soldiers returning from duty in Afghanistan. For simplicity, I shall refer to this source as "the media," mostly because other sources will need access to publicity to spread their message. It is surely heroic to assume that the media does not have any political bias either in favor or against the leader. On the other hand, in many free societies the media does not present a unified stance on any political issue. These now imply that the signal received from this source is noisy and potentially biased. To take into account noise, I shall assume that although the media signal is correlated with actual policy quality, it will be imperfectly so. To deal with bias, I shall allow the signal to be biased in favor of the leader (over-reporting good news and under-reporting bad news), or in favor of the opposition (under-reporting good news and over-reporting bad news), or neutral (equally likely to report either). As we shall see, the model will be flexible enough to accommodate variations on these three poles.

The theoretical research on the relationship between this "exogenous" source of information and audience costs is very sparse. Baum (2004) focuses on when leaders will want to generate audience costs by attracting the public's attention to the issue through the media. He takes it as unproblematic that the leader can actually generate these costs. As he notes, "such costs are generated whenever a leader issues a public threat, but their negative consequences are suffered only if the leader backs down and the public is aware of the threat and is institutionally capable of inflicting punishment" (606, emphasis in original). As I have explained above, public awareness is not sufficient to generate these costs, there must be a credible willingness to do so. This model is then the first attempt to model specifically the impact of media signaling on citizen evaluation of the government, albeit in a drastically simplified setting. ${ }^{10}$

It is worth emphasizing that my approach assumes that citizens are fully strategic actors and attempt to make best possible use of the information available to them. They can freely replace an incumbent if they so choose or revolt if the leader has repressed the opposition, thereby removing the election option. To decide what to do, citizens use all the information provided by the strategic actions of the politicians and the reportage by the media. This means that citizens are both prospective and retrospective: they make their decisions on the basis of expectations for the future but they derive these expectations from the incumbent's past performance and their beliefs about the untested challenger's future performance. ${ }^{11}$

to lie. However, this would beg the original puzzle: why would citizens adopt such strategies with respect to the opposition? Ascribing blame or credit for a policy that the opposition had no hand in implementing is a dubious assumption that would require a theoretical investigation of its own.

${ }^{10}$ It is worth noting that there is some correspondence between the media signal and the information provided by the state of the economy in classic diversionary war models (Richards et al. 1993, Smith 1996a). However, whereas noisiness is common to both, bias has no natural interpretation in these models.

${ }^{11}$ See Fiorina (1981) on retrospective voting and Miller and Wattenberg (1985) for an empirical evaluation of prospective and retrospective factors in voter evaluation of candidates. 


\subsection{Regime Type and Political Failure}

One way of defining political failure is by analogy with market failure as the case where there exist policies that Pareto dominate the equilibrium policy choices (Besley and Coate 1998). The definition in this article is analogous: political failure occurs when leaders pursue actions that citizens would not want pursued if they knew everything the leader knows. That is, repealing good policies and continuing bad ones.

I define two types of political failure: In Type I failure, the leader repeals good policies; and in Type II failure, the leader continues bad policies. ${ }^{12}$ The question becomes: under what conditions would political failure occur, and if it does, what type is it likely to be?

The next natural question is to ask whether different regimes are more or less susceptible to political failure. Fearon (1994a) surmises that since democracies have elections as a low-cost way for citizens to express their disapproval, democratic regimes should be able to generate audience costs at higher rates than non-democratic ones. That is, the magnitude of audience costs is increasing with the openness of the political regime.

As Schultz (2001a) notes, whereas it is easier to remove democratic leaders, their punishments will tend to be a lot less severe than those for removed authoritarian leaders. Therefore, it is unclear under which regime type the selection threat will be more credible. However, he argues that the magnitude of audience costs is not as important as the ability to convey that they exist to the foreign rival.

I conceptualize regimes along two dimensions. First, in terms of the efficacy and costliness of the repressive apparatus available to the government. Whereas some regimes do make any sort of opposition illegal, most contemporary ones tend to put a façade of legitimacy by seemingly allowing it. Instead of assuming the effectiveness of opposition, I prefer to derive it from a more basic model, in which all opposition is potentially effective, but may turn out to be actually ineffective because of the strategies it pursues. As we shall see, it is the credibility of the threat of repression that influences opposition's behavior and its ultimate effectiveness. Anticipating some of the results, I note that even a potentially effective opposition becomes nothing but a blind supporter of government policy in repressive societies. One difference is that this is now equilibrium behavior, not an assumption in the model.

Second, regimes differ in terms of the bias of the alternative sources of information. Whereas all such sources will be noisy, the signal to noise ratio will vary according to how protected from government interference these sources are. Citizens in a polity with constitutionally protected media freedoms, for example, will be more likely to receive both good and bad news from an exogenous source of information than citizens in a policy with tightly-controlled media. Thus, a democracy would be characterized by high costs of repression and high signal to noise ratio in the exogenous signal. Conversely, an authoritarian regime would be characterized by low costs of repression and an exogenous signal biased toward good news. Mixed-regimes, on the other hand, would have intermediate costs of repression with varying degrees of control of alternative sources. This setup allows us to examine variations among regimes types but also within types (e.g. democracies that differ

\footnotetext{
${ }^{12}$ Heuristically, these are intended to parallel the two errors in statistical hypothesis testing, where Type I error means erroneously rejecting a correct null hypothesis, whereas Type II error means erroneously failing to reject a wrong null.
} 
in the amount of protection offered to media).

With these ideas in mind, I present a simple stylized formalization of a strategic interaction among three strategic players-leader, opposition, citizens-and a non-strategic one-the media. Before presenting a formal specification of the model, it will be useful to discuss several of its simplifying assumptions.

\section{A Theoretical Model of Domestic Interaction}

\subsection{Substantive and Theoretical Motivations of Assumptions}

The model is not a faithful description of reality but an analytic tool to sharpen our intuitive understanding of the phenomena I identified in the preceding section. By reducing the strategic context to a very stark and small (but certainly not minimal) set of actions, it can illuminate the conditions that are most conducive to political failure. To this end, I assume non-rival, non-excludable (public good) policies and a homogenous electorate. These two assumptions abstract away from distributive conflict and coordination problems.

First, a public good policy implies that the leader cannot selectively target a subset of the electorate with benefits to ensure his survival in office. Although this is much less sophisticated than the current leading theory of leader survival by Bueno de Mesquita et al. (2003), it can be defended on the grounds that interstate crises (or wars) are events whose outcomes do not really have common or private good attributes. Although one can imagine benefits and costs accruing differently to various segments of the population, national humiliation or victory in war seem overall to be prime examples of cases where distributional conflict does not have much pull.

Second, a homogenous electorate implies that we can restrict analysis to the behavior of a single representative voter. Although one could justify this with an appeal to the median voter theorem, I prefer to think about it as a first-cut assumption that makes sense given that I have already excluded distributional conflict. Its separate contribution is to assume away coordination problems that voters with different priors may encounter when they attempt to decide whether to oust the incumbent.

These two assumptions give the informational theory the most permissive environment where it can operate, a strategic context that is entirely defined in terms of the informational asymmetries. Here, information is decisive: no group of citizens can be bought off by selective disbursement of private or public goods; moreover, the leader cannot depend on low turnout or strategic voting to survive if his policies are revealed to be flawed. If audience costs are difficult to generate in this environment, then they will be even more so in more realistic ones.

To focus on the domestic incentives for information transmission, the model follows Smith $(1996 a)$ in simplifying the environment by ignoring the presence of a foreign actor. Insofar as a decision to continue a bad policy rests with the government which can always repeal it, this assumption should not be too distorting. To see this, note that because actor preferences are aligned with respect to policy quality, all three of them (leader, opposition, citizens) will evaluate a particular policy in exactly the same way, as either good or bad. With respect to foreign policy, this would include the desirability of a pursuing a bluffing strategy, and it would take into account the likely reactions of the foreign actor. In other 
words, if a particular policy is optimal in equilibrium for a larger game with a foreign actor, then all three domestic actors would agree that it is so.

The problem of political failure does not arise from the interaction with the foreign state but from the leader's incentives to distort available information for office-seeking purposes. This means that the focus should not be on how the foreign actor will react, as this is something all domestic actors will concur about, but on how the leader can conceal the fact that he has implemented a bad (foreign) policy in the area where he is supposedly much more competent. If the strategy is bad (e.g., unlikely to end in securing concessions from the foreign actor), the leader realizes that he should repeal it and the citizens would want him to. If he fails to do so, citizens would want to punish him and the foreign actor's behavior at this point is irrelevant: it has already been taken into account when determining the desirability of the policy. Hence, the two assumptions allow me to abstract away from the behavior of the foreign actor, and to concentrate on the informational microfoundations of domestic audience costs.

\subsection{The Model}

To characterize policy failure in a state with possibly restricted political competition, I present a simple two-period analytical framework, which builds on Dur (2001). The nation consists of a large number of identical citizens, each of whom derives utility from an existing public good policy depending on its quality. The preferences of the representative citizen are entirely policy-based, and the citizen receives $b \in(0,1)$ if the policy is good, $-b$ if the policy is $b a d$, and 0 if no policy is currently in place. ${ }^{13}$

Office-holders are drawn from the population of ordinary citizens but in addition to the policy benefits, they obtain ego rents, $v \in(0,1)$, from holding the position of leadership. I assume that all else equal, ego rents are more important to office-holders than policy benefits. In other words, the leadership position is highly desirable.

At the beginning of each period, the current leader implements a policy, which can turn out to be either good or bad. The policies implemented by more competent leaders are more likely to be good. Denote the probability that the policy is good by $p$ if it is chosen by a competent leader, and $q<p$ if it is chosen by an incompetent one. The common prior probability that the incumbent is competent, is $\mu$, and thus, the probability that the existing policy is good is $g=\mu p+(1-\mu) q$. Leader's competence is unobservable and unknown to all players, including the leader. ${ }^{14}$

An opposition competes with this leader for office, which it may obtain either through

\footnotetext{
${ }^{13}$ This eliminates distributive politics. While one can imagine many situations in which it will be reasonably satisfied (e.g. losing a war is a universal bad), the reason for having it in this model is to create an environment in which whatever distortion occurs in the leader's behavior would be due entirely to informational issues. It is not difficult to generate inefficient behavior in distributive settings where some fraction of the population likes one policy and others prefer another.

${ }^{14}$ This is a departure from existing models where the incumbent knows his own competence, but the flavor is quite similar. I prefer the policy quality formulation because it is more natural to think of the exogenous source report being conditional on the policy, and not on the intrinsic characteristics of the leader. Given the two possible pieces of private information a leader could possess (policy quality and own competence), it would complicate the model considerably to consider both, hence the assumption that the leader does not know, and therefore cannot condition his behavior on, his own competence.
} 
elections or revolution, which we collectively call the citizen's selection. In both cases, only the citizens can put the opposition in office by replacing the leader. The probability that the opposition is competent is denoted by $\mu^{o}$ and is drawn randomly immediately prior to the citizen's selection from the uniform distribution function $F(\cdot)$, and so $F(\mu)$ is the probability that $\mu^{o} \leq \mu .^{15}$ Let $\mu_{e}^{o}$ denote the ex ante expected value of the opposition competence. Under the information structure specified below, the fundamental difference between the leader and the opposition is that while citizens may be able infer something about the incumbent's competence, they have no way of knowing anything about the opposition's. ${ }^{16}$ Further, the opposition has no way of evaluating its own competence until it actually governs and observes the quality of the policy it implements.

While both the leader and the opposition observe a perfectly informative signal about the policy quality before taking any actions, citizens can only observe a noisy signal and only if the policy does not get repealed. There are two possible signals from non-repealed policies, success and failure. A good policy produces success with probability $\alpha \in(1 / 2,1)$; and a bad policy produces failure with probability $\beta \in(1 / 2,1)$. That is, good policies are more likely to send the positive signal than bad policies. These signals come from an exogenous non-strategic source of information. For simplicity, I shall sometimes refer to them as "policy outcomes" with the understanding that the main concern is with the probability that the "outcomes" correctly reflect the quality of the policy in place. A governmentcontrolled source would be biased toward reporting success in the sense that the probability of a good policy producing the success outcome is very high, while the probability of a bad policy producing failure is quite low. An extremely unbiased source would generate these outcomes with correspondingly high probabilities, allowing the citizens to infer policy quality with great precision.

The sequence of the game is as follows. In each period, chance determines the quality of the existing policy, and both the leader and the opposition learn it. In the first period, the leader may then repeal the policy or continue it. Continuing the policy enables the opposition to endorse it or dissent. Should the opposition dissent, the leader can repress it, which eliminates the possibility of elections and instead leaves the citizens with the option of a costly revolution. In all other cases, citizens may costlessly replace the leader with the opposition. In cases of non-repealed policies, citizens observe the noisy signal about their quality immediately prior to their selection, which is binding. Figure 1 illustrates the sequence of actions in the first period of the game. In the second period, there is no citizen's selection, and so the period ends with the incumbent's decision whether to repeal the policy or continue it.

Society is endowed with an institutional structure that determines the costliness and efficacy of the repressive instrument. Let $c \in(0,1)$ denote the cost that the leader must pay

\footnotetext{
${ }^{15}$ The consequence of this assumption is to exclude cases where the leader is certain to stay in office or be removed regardless of the policy decision. In these cases there are no incentives to distort information. The assumption of uniform distribution does not affect the results but does help in simplifying notation and math.

${ }^{16}$ This structure can be found in many other models. Rogoff (1990) provides a canonical example and also justifies it on the basis of empirical findings that show that "for U.S. presidential elections voters do not take into account the opposition's party economic performance when last in power" (footnote 10 in that article). Further, as Eisinga, Franses and van Dijk (1998) show for the Netherlands, citizens tend to be quite uncertain about the way they would vote until right before the election, which justifies the timing of the random draw of the opposition's competence in the model.
} 


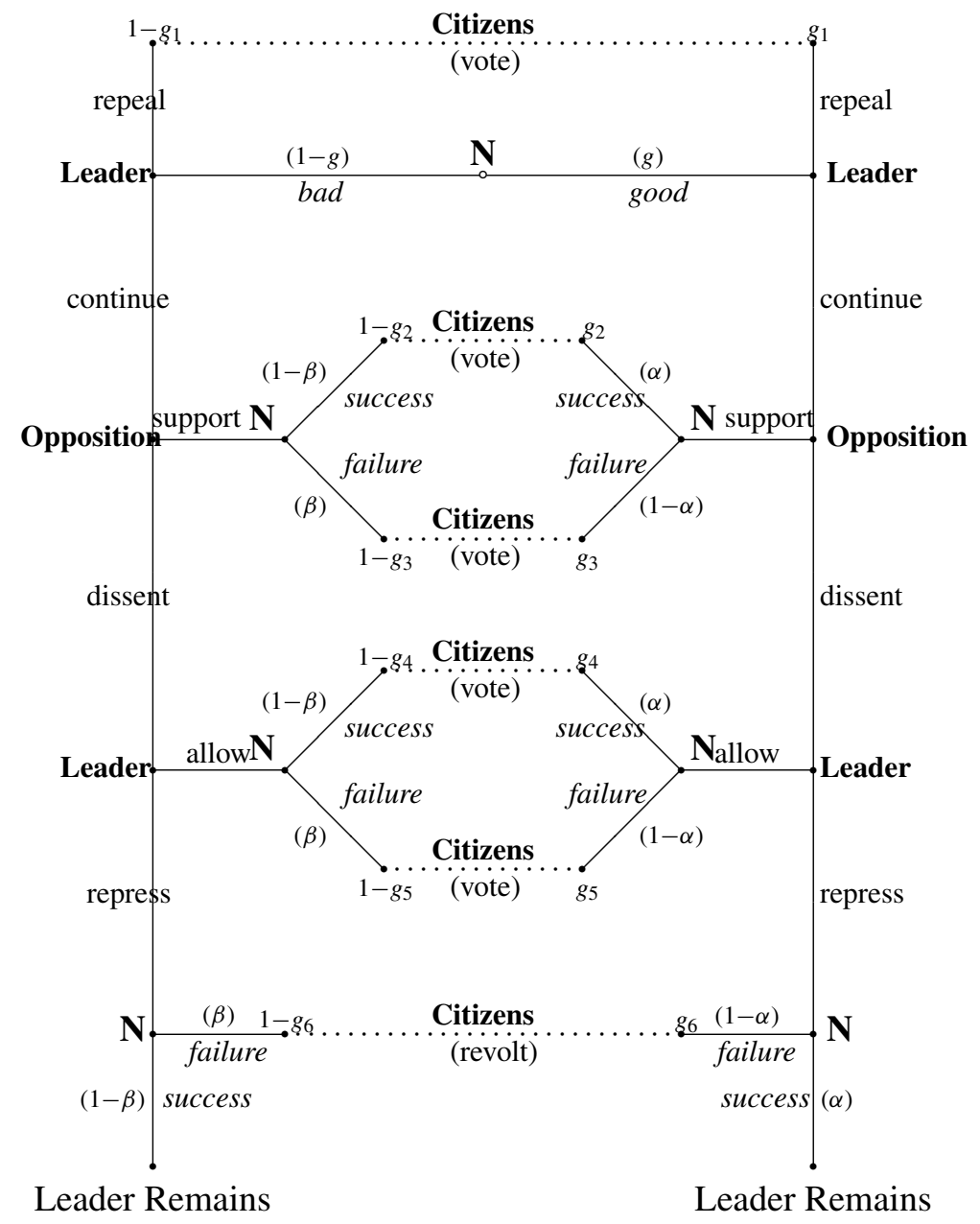

Figure 1: Schematic Representation of the First Period of the Game.

for using repression, and let $(1-c)$ denote the costs suffered by the opposition whenever it gets repressed. ${ }^{17}$

Citizens also have to pay for removing an incumbent through revolutionary means. Let $k \in(0,1)$ denote the cost of rebeling. There is no obvious relationship between $k$ and how painful the revolution will be to the leader. I assume that violent removal is catastrophic, with the leader losing at least the equivalent of the ego rents.

I make two simplifying assumptions when it comes to outcomes. First, if repression is followed by policy success, the leader stays in office with certainty. Repression raises the

\footnotetext{
${ }^{17}$ That is, the amount of suffering repression causes declines as the costs of using the apparatus increase. This is intuitive when conceptualized in terms of institutional constraints: as the costs of using the apparatus increase, the effectiveness of repression declines. In a democracy it would be very costly to engage even in minor suppression of the opposition (high costs to leader, low costs to opposition), while in a dictatorship it would be relatively easy to eliminate the opposition entirely (low costs to leader, high costs to opposition). The formulation above is the simplest way to capture this intuition that would allow to do comparative statics on the institutional features of different regimes.
} 
costs of replacing the leader, and policy success can only raise them even higher because the repressive apparatus is unlikely to have been damaged, which is what may happen following policy failure. Second, if the citizens revolt, the revolution succeeds. The basic results do not change if we make revolutionary success a probabilistic event although the expression become quite a bit more cumbersome.

\section{The Citizen Strategy}

At the time of selection, the policy outcome in the first period is realized and the policy benefits are sunk. The citizens will only care about the expected payoff in the next period. In the second period, the (possibly new) incumbent has no reason to distort policy for electoral gain. Therefore, all leaders repeal bad policies and continue good ones. This strategy is optimal regardless of the competence of the incumbent.

The citizens' choice is therefore between keeping a leader about whose competence something can be inferred from strategies and policy outcome in the first period, or replacing that leader, possibly at some cost. How do citizens update their beliefs about the leader's competence?

Whenever the policy quality is known (either observed directly by the leader and the opposition, or inferred from the strategies and outcome by the citizens), it is possible to update beliefs about the competence of the leader by Bayes rule. The posterior belief is then:

$$
\hat{\mu}= \begin{cases}\frac{\mu p}{\mu p+(1-\mu) q} \equiv \mu^{G} & \text { if the policy is good, } \\ \frac{\mu(1-p)}{\mu(1-p)+(1-\mu)(1-q)} \equiv \mu^{B} & \text { if the policy is bad. }\end{cases}
$$

It is not difficult to show that because $p>q$, it follows that $\mu^{G}>\mu>\mu^{B}$.

Given the strategy of the incumbent in the second period, the expected payoff for the citizens is $\pi(\hat{\mu})=b[\hat{\mu} p+(1-\hat{\mu}) q]$, where $\hat{\mu}$ denotes the probability that the incumbent is competent. Because $p>q$, it follows that $\pi(\cdot)$ is strictly increasing in $\hat{\mu}$. In words, the expected payoff to the citizen is strictly increasing in the expected competence of the incumbent.

To simplify notation, I shall use $\pi^{G} \equiv \pi\left(\mu^{G}\right)$, and $\pi^{B} \equiv \pi\left(\mu^{B}\right)$ to denote the expected payoffs based on beliefs about leader's competence when the policy is good and bad, respectively. Similarly, I shall use $\pi_{e}^{o} \equiv \pi\left(\mu_{e}^{o}\right)$ when beliefs are based on expected competence of the opposition.

Because the citizens observe the probability that the opposition is competent, $\mu^{o}$, prior to making their choice, the expected payoff from replacing the incumbent is $\pi\left(\mu^{o}\right)$. Letting $\hat{g}$ denote the posterior probability that the first-period policy was good, the expected payoff from retaining the incumbent is $\hat{g} \pi^{G}+(1-\hat{g}) \pi^{B}$. Let $K=0$ when the selection is done through elections, and $K=k$ when selection is done through revolution. The citizens will retain the incumbent whenever $\hat{g} \pi^{G}+(1-\hat{g}) \pi^{B} \geq \pi\left(\mu^{o}\right)-K$, or, expressed directly in terms of beliefs, whenever $\hat{g} \mu^{G}+(1-\hat{g}) \mu^{B} \geq \mu^{o}-K /[b(p-q)]$.

Let $e=1$ denote a decision to retain the leader, and $e=0$ denote a decision to replace the leader with the opposition. The citizens' decision rule is a function of the updated beliefs 
and is given by:

$$
e(\hat{g}, K)= \begin{cases}1 & \text { if } \quad \hat{g} \geq \frac{\mu^{o}-\mu^{B}}{\mu^{G}-\mu^{B}}-\frac{K}{(p-q)\left(\mu^{G}-\mu^{B}\right)} \\ 0 & \text { otherwise. }\end{cases}
$$

In other words, the citizens will keep the leader if they believe that first-period policy was good with sufficiently high probability. This, of course, gives the leader incentives to conceal information when the policy is bad, which may in turn lead to policy distortions for electoral gain. On the other hand, it also gives the opposition an incentive to reveal the information when the policy is bad to obtain electoral advantage.

Note that the belief required to retain the leader in elections is strictly higher $(K=0)$ compared to the belief necessary to retain the leader by not revolting. If citizens re-elect the leader given some belief about competence, they will never revolt if they have this belief. The converse, however, is not true. There is a range of (pessimistic) beliefs where citizens would not revolt but would replace the leader in elections if given a chance. When the only option is a costly revolution, the citizens must be convinced that the leader is truly incompetent to engage in violence. Thus, the leader will have incentives to confront the citizens with a choice between two unpalatable alternatives: retain someone they believe is not very competent, or overthrow the leader violently at great cost.

While the citizen's choice is deterministic (because at the time selection takes place $\mu^{o}$ is realized and observable), selection appears probabilistic to the other players. Rewriting the decision rule in terms of the opposition's competence yields:

$$
\mu^{o} \leq \hat{g} \mu^{G}+(1-\hat{g}) \mu^{B}+\frac{K}{b(p-q)} \equiv \bar{\mu},
$$

and thus the ex ante probability that the citizens will retain the leader is $\operatorname{Pr}\left(\mu^{o} \leq \bar{\mu}\right)=$ $F(\bar{\mu})$. I now make the following assumption to make the game substantively interesting:

ASSUMPTION 1 (Selection Incentives). $\mu^{o} \sim U\left[\mu^{B}, \mu^{G}\right]$.

That is, $F(\cdot)$ is the uniform distribution with support $\left[\mu^{B}, \mu^{G}\right]$. This assumption implies that if citizens know that the policy is good, they always re-elect the leader: $F\left(\mu^{G}\right)=1$. If they know that the policy is bad, they always replace the leader: $F\left(\mu^{B}=0\right)$. This assumption further implies that the citizens will never revolt when they know that the policy is good.

The results do not depend on this distribution being uniform. However, the assumption considerably simplifies notation because the probability that citizens retain the leader in elections is:

$$
F\left(\hat{g} \mu^{G}+(1-\hat{g}) \mu^{B}\right)=\frac{\hat{g} \mu^{G}+(1-\hat{g}) \mu^{B}-\mu^{B}}{\mu^{G}-\mu^{B}}=\hat{g} .
$$

That is, calculations can be done directly in terms of beliefs at the information sets, which also allows for simple closed form expressions in the solutions. The citizens have six information sets in this game. Figure 1 lists the notational shortcuts, $g_{i}$ for all $i \in 1,2, \ldots, 6$, that denote the citizens' beliefs that the policy is good at these sets. The probability that citizens retain the leader following repression is:

$$
\gamma_{6} \equiv g_{6}+m, \quad \text { where } \quad m \equiv \frac{k}{b(p-q)\left(\mu^{G}-\mu^{B}\right)}>0 .
$$


Let $V^{j}=v+\pi^{j}$ with $j=G, B$ denote the leader's policy quality-dependent expected payoff from retaining office, let $V_{e}^{o}=v+\pi_{e}^{o}$ denote the opposition's expected payoff from gaining office, and assume that being in office is rewarding:

Assumption 2 (Office-Seeking). $v>b+b(p-q)\left(\mu^{G}-\mu^{B}\right)$.

We now have $V_{e}^{o}-\pi^{G}=v+\pi_{e}^{o}-\pi^{G}=v-b(p-q)\left(\mu^{G}-\mu_{e}^{o}\right)>0$, where the inequality follows from the assumption and $\mu_{e}^{o}>\mu^{B}$. The assumption therefore implies that $V_{e}^{o}>\pi^{G}$. That is, the opposition's expected payoff from holding office is strictly greater than what it would get if a leader whose policy happens to be good remains in office. In other words, the opposition has incentives to seek office even when the policy implemented by the leader is good. ${ }^{18}$

\section{The Unique Fully Revealing Efficient Equilibrium}

An equilibrium is fully revealing if in it citizens are able to infer the policy quality with certainty from the strategies of the other players. It is partially revealing if they can do so probabilistically. It is uninformative if the only new information comes from the noisy signal. Audience costs are only meaningful in fully or partially revealing equilibria because these are the only equilibria in which the probability of political failure depends on the citizens' selection decision.

The following proposition, whose proof is in Appendix A, demonstrates that if the costs of repression are intermediate, then there exists a unique fully revealing equilibrium.

PROpOSITION 1. Let $\underline{c}=V^{B}-\pi_{e}^{o}<V^{G}-\pi_{e}^{o}=\bar{c}$. If the costs of repression are intermediate, that is if $c \in[\underline{c}, \bar{c}]$, then there exists a unique fully informative equilibrium in which the leader continues good policies and repeals bad ones; the opposition supports only good policies, and the leader represses dissent only when the policy is good. The citizens always retain leaders who continue policies, and remove leaders who repeal policies.

Intuitively, if the costs are too high $(c>\bar{c})$, then repression will not be optimal for the leader when the policy is good even if repressing would convince the citizens the policy is good while not repressing would convince them it is bad. Repression is simply too expensive. On the other hand, if the costs are too low $(c<\underline{c})$, then repression is too cheap and it is worth repressing dissent unless allowing it would convince the citizens that the policy is good.

Because $\underline{c}<\bar{c}$, the interval $[\underline{c}, \bar{c}]$ exists for any value of the priors. Whenever repression costs are in this range, the leader strictly prefers to allow dissent and be removed instead of repressing and keeping office. The reason is that when the policy is bad, the leader's own estimate of the expected payoff of remaining in office is low because of the updated belief of competence relative to the expected competence of the opposition. Then, if the costs are not too low, the double whammy of a policy expected to be worse in the next period and the costs or repression necessary to ensure remaining in office outweighs the ego-rents, and the leader prefers to "go quietly into the night."

\footnotetext{
${ }^{18}$ This assumption can be replaced by the more intuitive, but a bit more restrictive, requirement that $v \geq 2 b$, which is another way of saying that ego-rents are at least twice the policy benefit from a good policy.
} 
This equilibrium is efficient because the probability of political failure is zero. Leaders continue only good policies and repeal only bad ones. How stringent are the conditions for its existence? The width of the cost range is:

$$
\bar{c}-\underline{c}=\pi^{G}-\pi^{B}=b(p-q)\left(\mu^{G}-\mu^{B}\right)=\frac{b \mu(1-\mu)(p-q)^{2}}{[\mu p+(1-\mu) q]-[\mu p+(1-\mu) q]^{2}}>0 .
$$

The maximum width, at $\mu=1 / 2$, is $\frac{b(p-q)^{2}}{(p+q)(2-p-q)}<b$. With reasonable values for $p$ and $q$ (that is, values such that it is not simultaneously the case that $p$ is close to 1 and $q$ is close to 0 ), the width is much smaller. This means that the range of costs that can sustain this equilibrium may be quite small indeed. In the numeric example below, the costs would have to be in the interval $[.6625, .7325]$, anything smaller or higher would not work, and this is the best-case scenario with $\mu=1 / 2$.

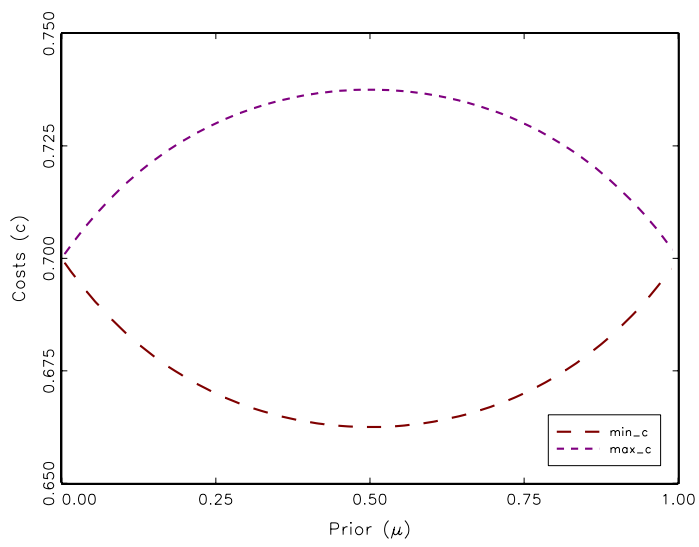

Figure 2: Cost Range for the Fully Informative Equilibrium $(p=.75, q=.25, b=.3)$.

The cost range dramatically shrinks as the prior beliefs are biased either for or against the incumbent (that is, as $\mu$ moves away from $1 / 2$ ), as shown in Figure 2. For each value of the priors, the costs that can support the fully revealing equilibrium are inside the lens shape. As the figure demonstrates, this range strictly decreases with any bias for or against the incumbent. This implies that the conditions for this equilibrium may be quite stringent if there is any significant bias in the priors regardless of the parameters. Thus, although this efficient equilibrium always exists if the repression costs are in the intermediate range, the condition may be restrictive. (I investigate other implications of comparative statics in Section 8.) What may one expect if the costs are outside that range? One important immediate consequence of Proposition 1 is:

COROLLARY 1. All other sequential equilibria are either partially revealing or uninformative. In all of them political failure occurs with positive probability.

There are no other equilibria in which the citizens can infer the policy quality with certainty from the strategies of the leader and the opposition. This means that there are no other equilibria in which the leader repeals only bad policies and continues only good ones. 


\section{Uninformative Equilibria: Failure Rate Independent of Exogenous Signals}

For the remainder of this paper, I analyze the properties of equilibria when the costs of repression are outside the range where the efficient equilibrium can be supported. This is made on the charitable assumption that in the presence of multiple equilibria, the most informative one will be selected (recall that we are investigating the best-case scenario for information transmission). ${ }^{19}$

\subsection{Repressive Society: Universal Endorsement}

Suppose that the repressive instrument is not too costly; that is, $c<\underline{c}$. In such a society the leader can credibly threaten to repress all forms of dissent regardless of policy quality. I first show that given these low costs of repression, it is optimal for the leader to repress all dissent. The necessary condition for repression to be optimal when the policy is good is:

$$
c \leq V^{G}-\pi_{e}^{o}-(1-\alpha)\left(V^{G}+v\right)\left(1-\gamma_{6}\right),
$$

and the analogous condition when the policy is bad is:

$$
c \leq V^{B}-\pi_{e}^{o}-\beta\left(V^{B}+v\right)\left(1-\gamma_{6}\right) .
$$

Because $0<m \leq \gamma_{6} \leq 1$, it follows that whenever $c \leq \underline{c}$, the condition in (3) will be satisfied as well. I now show that (3) is, in fact, the binding condition that ensures that repression is optimal regardless of policy quality. Subtracting (3) from (2), and using $\beta>\frac{1}{2}>1-\alpha$, yields: $V^{G}-V^{B}+\left(1-\gamma_{6}\right)\left[\beta\left(V^{B}+v\right)-(1-\alpha)\left(V^{G}+v\right)\right]>$ $\left[\frac{1+\gamma_{6}}{2}\right]\left(V^{G}-V^{B}\right)>0$. This means that if condition (3) is satisfied, then (2) will be satisfied as well. That is, if it is optimal to repress when the policy is bad, it is also optimal to repress when it is good. As we have seen, optimality of repression when the policy is bad is ensured whenever $c \leq \underline{c}$. We conclude that in this case, repression is optimal regardless of policy quality.

Given that the leader represses dissent, in any equilibrium the opposition must be supporting both the good (by Lemma 6) and the bad (by Lemma 3) policies. If the leader always represses, then the opposition always endorses. By Corollary 1, in all these equilibria the leader either always continues the policies or always repeals them. Therefore, there are two pure-strategy equilibria when $c<\underline{c}$ : In both, the leader always represses and the opposition always dissents; in one of them, the leader repeals all policies, and in the other the leader continues them.

Let $g_{A}$ solve the equation $g=\frac{b}{V^{B}-\pi_{e}^{o}}$, and let $g_{B}$ solve the equation $g=\frac{b}{V^{G}-\pi_{e}^{o}}$. Note that $V^{B}<V^{G} \Rightarrow g_{A}<g_{B}$. The following proposition, whose proof is in Appendix A, establishes the existence of these uninformative equilibria.

\footnotetext{
${ }^{19}$ Characterizing all sequential equilibria is rather tedious, and many of them can be eliminated as unintuitive (Cho and Kreps 1987). The complete characterization of the game's equilibria and other proofs are available from the author. All other pure-strategy equilibria with the leader playing a separating repressive strategy are unintuitive. This leaves only equilibria where the leader pools on repression or no repression. Further, equilibria where the leader allows dissent always but the opposition plays a separating strategy inducing the leader to repeal all policies are also unintuitive. Thus, we only have two sets of uninformative equilibria, where both the leader and the opposition play pooling strategies.
} 
PROPOSITION 2. If $c<\underline{c}$, then there exist sequential equilibria in which the leader always represses dissent, and the opposition endorses all policies regardless of quality. If the prior belief that the policy is good, $g \in\left[g_{A}, g_{B}\right]$, then only Type I failure can occur (leader repeals all policies). If $g \geq g_{B}$, then both failures can occur but with $g$ sufficiently high, only Type II failure (leader continues all policies) is intuitive.

If citizens attach a relatively low initial probability to the policy being good, then the leader will not continue policies, and so the only failure possible is that good policies get repealed. The reason for this is intuitive: Because in these uninformative equilibria citizens can only rely on the noisy signal to infer information, their updated beliefs will generally not be sufficiently favorable to the leader (because the prior is so low) to induce continuation of bad policies. On the other hand, if they are quite optimistic, then the leader may keep the policies.

\subsection{Non-repressive Society: Endorsement Babble}

Suppose now that the repression instrument is quite costly: $c>\bar{c}$. The leader can never credibly threaten to repress dissent. All uninformative equilibria in this case involve the leader allowing dissent regardless of policy quality. To see this, note that allowing dissent when the policy is good is optimal whenever:

$$
c \geq\left(V^{G}-\pi_{e}^{o}\right)\left[1-\alpha g_{4}-(1-\alpha) g_{5}\right]-(1-\alpha)\left(V^{G}+v\right)\left(1-\gamma_{6}\right) .
$$

The necessary condition (at $g_{4}=g_{5}=1$ ) is always satisfied because $c>0$. Further note that the sufficient condition (at $g_{4}=g_{5}=0$ ) is the converse of the necessary condition for repression in (2). Recalling that $\bar{c}=V^{G}-\pi_{e}^{o}$ from (8), we conclude that whenever $c>\bar{c}$, condition (4) will be satisfied.

Optimality of allowing dissent when the policy is bad requires: $c \geq\left(V^{B}-\pi_{e}^{o}\right)[1-(1-$ $\left.\beta) g_{4}-\beta g_{5}\right]-\beta\left(V^{B}+v\right)\left(1-\gamma_{6}\right)$. As before, the necessary condition is always satisfied. The sufficient condition is the converse of (3). We have already seen that this bound is strictly smaller than (2), and conclude that (4) is the binding condition, That is, if it is optimal to allow dissent when the policy is good, it is also optimal to allow it when the policy is bad. Thus, whenever $c \geq \bar{c}$, allowing dissent regardless of policy quality is optimal.

When the leader allows dissent, the opposition is free to choose any strategy available. However, if it plays any separating strategy, then, by Corollary 1, in equilibrium the leader always repeals policies and does not allow it to signal quality to the citizens. These Type I failure equilibria, however, are all unintuitive. To see why, note that the leader could instead continue the good policy if that would convince citizens of its quality, but because the opposition is playing a separating strategy, continuing the bad policy cannot benefit from the updated belief because it reaches a different information set.

This leaves four equilibria in pure strategies in this range: the opposition either always dissents or always endorses, and the leader either always repeals or always continues the policy. The following proposition, whose proof is in Appendix A, establishes the existence of these uninformative equilibria.

PROPOSITION 3. If $c>\bar{c}$, then there exist sequential equilibria in which the leader always allows dissent, and the opposition either always endorses or always dissents. If the 
prior belief that the policy is good, $g \in\left[g_{A}, g_{B}\right]$, then only Type I failure can occur. If $g \geq g_{B}$, then both failures can occur but with $g$ sufficiently high, only Type II failure is intuitive.

This parallels the results for repressive societies: citizens are unable to infer policy quality from the strategies of the leader and the opposition. The reason is slightly different, however. In a repressive society, the threat to repress is always credible, and so the opposition never dissents from any policies, which means citizens cannot learn anything from the strategies. In a non-repressive society, the threat to repress is never credible, and so the opposition can say whatever it wants, and given that it wants citizens to believe the policy is bad, its pronouncements about quality are never believable, and so the citizens cannot learn anything either. Only when the partially credible repressive threat induces the opposition into truth-telling can full information disclosure occur.

Note further that the non-strategic signal plays no role in the probability of political failure occurring in either the universal support or endorsement babble equilibria. Although citizens do infer information from the signal, their behavior does not affect the leader's strategy: leaders either always repeal or always continue all policies. The rate of failure only depends on the citizens' priors, that is, their bias toward or against the leader. If they are positively disposed, then leaders continue all policies. If they are not, then leaders repeal all policies.

In the next section I investigate the properties of partially revealing equilibria, in which the probability of failure does depend on the quality of the non-strategic signal, and which do exist even for pessimistic priors (recall that if citizens are quite pessimistic, $g<g_{A}$, then the pure-strategy equilibria do not exist).

\section{Partially Revealing Equilibria: Endogenous Rate of Failure}

While the results of the preceding section may appear discouraging, they do not tell the entire story. We have yet to investigate the role of noisy signals in depth. In the fully revealing equilibrium, these signals play no role because citizens are able to infer policy quality from the strategies of the informed players. In the uninformative equilibria, citizens do update based on these signals but this is not sufficient to induce the informed players to adopt even semi-separating strategies. What role, then, can these exogenous signals have?

The model allows for exogenous signals of varied quality. If both $\alpha$ and $\beta$ are close to 1 , then the signals are of very high quality because they reveal the policy type with near certainty. Conversely, low values of these parameters imply very noisy signals. It is also possible to examine the bias of these signals. For example, keeping $\alpha$ close to 1 but $\beta$ low describes the situation where the signals are biased toward good news in the sense that if the policy is good, they would report that with very high probability but if it is bad, the corresponding probability is low.

If the probability of failure depends on the quality of the exogenous signals, then the leader must be playing a mixed strategy at the repeal stage. By Lemma 2, these equilibria cannot involve continuing the bad policy with certainty while repealing the good one with positive probability. Thus, we shall look for equilibria in which the leader continues good 
policies always, and continues bad ones with probability $r$. The equilibrium probability $r^{*}$ is then the endogenously determined rate of (Type II) failure.

Suppose then that the leader plays this semi-separating continuation strategy. By lemmas 4 and 5 it follows that the opposition and the leader must be pooling at the remaining information sets. The discussion and the result in this section is stated for the case where the opposition always dissents and never gets repressed, but the cases of the opposition always supporting and the leader pooling on repression or non-repression can be easily established analogously.

Thus, suppose $c>\bar{c}$ and suppose the leader continues good policies always, and continues bad ones with probability $r$. The optimality of the leader allowing dissent and the opposition always dissenting is established in the proof of Proposition 3. By Bayes rule, $g_{1}=0$ because conditional on observing repeal, citizens would conclude the policy must have been bad because good policies are never repealed. Further by this rule, the posteriors at the two information sets along the equilibrium path are:

$$
g_{4}=\frac{g \alpha}{g \alpha+(1-g) r(1-\beta)} ; \quad g_{5}=\frac{g(1-\alpha)}{g(1-\alpha)+(1-g) r \beta} .
$$

Continuing the good policy is always optimal because repealing it yields (at $g_{1}=0$ ) exactly $\pi_{e}^{o}<b+\pi_{e}^{o}$, which is the least the leader could get by continuing it.

Since the leader is willing to randomize when the policy is bad, it follows that the payoff of repeal and continuation are the same. Repeal gets $\pi_{e}^{o}$ and continuing gets $-b+\pi_{e}^{o}+$ $\left(V^{B}-\pi_{e}^{o}\right)\left[(1-\beta) g_{4}+\beta g_{5}\right]$. Setting these payoffs equal to one another and solving yields:

$$
(1-\beta) g_{4}+\beta g_{5}=\frac{b}{V^{B}-\pi_{e}^{o}} .
$$

At $r=0$, we have $g_{4}=g_{5}=1$ (that is complete separation). This cannot be an equilibrium because the leader has an incentive to continue the bad policy if winning the election is guaranteed (as it would be with these beliefs). At $r=1$, we have a pooling equilibrium only when $(1-\beta) g_{4}+\beta g_{5} \geq \frac{b}{V^{B}-\pi_{e}^{o}}$; that is, only when the prior $g$ is sufficiently high.

Otherwise, we can solve (6) for any prior $g \in(0,1)$, and find the optimal $r^{*}$ that satisfies it. To find this probability, we use (5) in (6), which yields the quadratic $A r^{2}+B r+C=0$ with coefficients $A=-(1-g)^{2} \beta(1-\beta) b, B=g(1-g)\left[\left(V^{B}-\pi_{e}^{o}\right) \beta(1-\beta)-b(1-\right.$ $\alpha-\beta+2 \alpha \beta)]$, and $C=g^{2} \alpha(1-\alpha)\left(V^{B}-\pi_{e}^{o}-b\right)$. The positive root (the only valid one because we need it to be a probability) is then $r^{*}=\frac{-B-\sqrt{B^{2}-4 A C}}{2 A}$. Since $A<0<$ $C$, the discriminant is always strictly positive, so the square root exists. If $r^{*} \leq 1$, the specified strategies constitute a sequential equilibrium, otherwise the Type II equilibrium of Proposition 3 exists. The above reasoning then yields the following result:

PROPOSITION 4. If $c>\bar{c}$, then there exists a sequential equilibrium in which the leader always allows dissent and the opposition always dissents. The leader continues good policies always and continues bad ones with probability $r^{*}$. The probability of (Type II) political failure, $r^{*}$, is strictly decreasing in the quality of the exogenous signal.

It is clear that there exists an analogous equilibrium with the opposition always endorsing the policy regardless of quality, and in fact the probability of continuing the bad policy is 
exactly the same. The comparative statics on the quality of the exogenous signal and their implications are in the section that follows. The intuition for the above result is straightforward. The opposition cannot reveal the policy quality credibly if the leader has no repressive threat. Given the opposition's babbling, the leader seems to have no incentive to reveal any information either. However, this turns out not to be the case in the presence of exogenous signals.

With these signals, the citizens can infer something about the policy quality anyway, reducing the incentives to persist in bad policies. If the signal to noise ratio of this exogenous source of information is high, then these incentives diminish significantly. That is, the threat of independent revelation of policy quality may help keep the leader in check. This is an imperfect mechanism, unlike the strategic one in the fully revealing equilibrium from Proposition 1, but a mechanism nevertheless. I now turn to the analysis of substantive implications of these findings.

\section{Discussion}

That citizens cannot rely on the government coming clean about what it knows is clear. Citizen control through the threat of the re-selection sanction alters the strategic incentives of the government even in our reduced context where their preferences over policies are identical. The government is usually better informed about the effects of its policies than the citizens. Unfavorable information would adversely affect its chances of retaining power because citizens would become pessimistic about its competence. Therefore, the government may seek to strategically misrepresent what it knows for electoral purposes.

We found that rational retrospective forward-looking citizens will attempt to infer the likelihood of getting good policies in the future by evaluating the past performance of the current leader. Should they become quite pessimistic about these prospects, they would replace the leader with the untried opposition unless doing so is prohibitively costly. That is, they can impose audience costs on the leader for pursuing policies contrary to the wishes of the citizenry.

The fate of the leader turns on the probability of this sanction, which depends on the citizen's beliefs and costs of replacement. Thus, the leader has a two-pronged strategy: obfuscate unfavorable information or raise these costs. However, its effectiveness may be blunted by the presence of an informed opposition with incentives to thwart the leader's attempts to hide such information. These incentives are themselves subject to distortion through the leader's repressive action.

Can the opposition credibly reveal to citizens the policy quality? In general, the answer seems to be negative. Only when the leader's repressive threat is partially credible can the opposition commit to a strategy that would reveal this information (Proposition 1). If repression is cheap, then the credible threat to stifle any dissent causes the opposition to endorse everything the leader does (Proposition 2). If repression is costly, then the opposition can do anything it wants with impunity because the leader cannot credibly threaten it with repression. This behavior cannot reveal information precisely because the opposition would always want the citizens to believe that the leader's policies are bad. Given this endorsement babble (mostly dissenting, but not necessarily so), the leader would appear to have no incentive whatsoever to condition the repeal strategy on anything but the citizen's 
prior estimate of its quality (Proposition 3). This polity can experience lots of dissent, but it will not be informative. Thus, from the strategic informational perspective, citizens under a democracy are no more able to learn the qualities of the policies implemented by their government than citizens under an autocracy. This allows us to contest the important claim that audience costs are linear in regime type. That is, that democracies are able to generate them at higher rates than other regimes. In this model, neither democracies nor autocracies can generate perfect costs:

HYPOTHESIS 1. All else equal, audience costs are not linear in regime type: they are nearly non-existent in autocracies, then sharply increase for mixed regimes, then decline again for democracies.

What happens in mixed regimes where the leader can credibly threaten to repress some, but not all, dissent? In these regimes, repeal signals unequivocally that policy is bad. Whereas both democrats and autocrats can repeal policies and remain in office, it is generally not possible for leaders in mixed regimes to do so. Further, even in the partially revealing equilibrium (Proposition 4) in which repeal also implies losing office, the probability of repeal is strictly smaller than the probability of the policy being bad. This suggests that leaders in mixed regimes are more vulnerable to audience costs, and hence:

HYPOTHESIS 2. Leaders in mixed regimes will have the shortest term in office following a policy repeal.

On the average, we expect that leaders in mixed regimes will be removed at higher rates than democrats or autocrats following repeal of some bad policy. For example, losing a war can be seen as repealing of a bad policy, and so our model would predict that leaders of mixed regimes would tend to lose office much more often than their counterparts in democracies or autocracies.

The fate of the Argentine junta after the Falklands War is illustrative. First, when Galtieri ousted Viola in December 1981, the brutality of the Dirty War that had exploded in 1976 and the regime's failed economic policies had split the armed forces and weakened the military's hold on power (Pion-Berlin 1985). Despite its control over the press and capacity for repression, at this time Argentina can be properly classified as a mixed regime rather than a full-blown authoritarian one. Second, the priors about the Malvinas policy were very favorable to the junta. When Argentina invaded the islands on April 2, 1982, a succession of governments had been trying to negotiate with Britain for years without success. Militarily, the goal was to seize the territory but the political goal was to force the British to the bargaining table rather than conquer the islands outright. At the time, both the junta and the Argentine populace believed the policy was good. ${ }^{20}$ The military's optimism continued through June 14-it estimated it could hold out for another 10 days to get the diplomacy and mediation moving. On the 15th, however, the newspapers broke the news that the garrison on the islands had surrendered, provoking passionate popular anger. The Generals

\footnotetext{
${ }^{20}$ The junta evaluated the chances of a military clash to be low because Britain was far and unlikely to fight without U.S. support, which the pro-American generals did not think was forthcoming. Because of their long collaboration with America, the generals gravely miscalculated Reagan's likely reaction (Burns 1987, pp. 14045).
} 
realized that the coercive strategy had failed despite Galtieri's insistence that the fall of Port Stanely meant that just a battle was lost, not the war. At this point the model would predict that the junta should repeal the policy, which is exactly what the military did, after Bignone replaced Galtieri in a bloodless coup the very next day. The military's entire rule was undermined and the armed forces yielded to the democratic civilian rule of Alfonsín within a year without attempting to resort to repression.

Because repealing a policy has such grave consequences for leaders of mixed regimes, one would expect the strongest resistance to such perfect signaling there. In other words, leaders in mixed regimes have great incentives to stick with a bad policy as long as the opposition and the citizens cannot infer for sure that it is bad. Once the leadership admits to its quality by repealing it, the game is up. Such considerations help explain why Germany prolonged its participation in the First World War and why its leaders got what they did once they surrendered (Goemans 2000).

Given that strategic information transmission will be very limited except in mixed-regimes, the exogenous source of information becomes quite important, even if imperfect, disciplining device (Proposition 4). This result, along with Proposition 1, demonstrates how audience costs can arise endogenously through two different mechanisms for information transmission: strategic behavior of the informed players (perfect audience costs) and nonstrategic revelation by a non-political source (weak audience costs).

Turning to the effect of the non-political source, Figure 3 demonstrates the probability of political failure across the entire range of citizen prior beliefs and for varying quality of the noisy signal. The $x$-axis represents the citizen's prior belief that the policy is good. This can be interpreted as their incumbent bias. Low values represent bias against the leader, and high values represent bias in leader's favor. The $y$-axis represents the probability that a bad policy generates a correct signal. ${ }^{21}$ The $z$-axis represents the probability that the bad policy is continued in equilibrium, and hence it represents the complement of the probability of audience costs being imposed.

The probability of political failure is increasing in the bias toward the leader. The more optimistic citizens are about the incumbent, the more likely is the latter to continue bad policies, and the less likely are citizens to impose audience costs on him for doing so:

HYPOTHESIS 3. All else equal, popular leaders will have difficulty generating audience costs.

The magnitude of this effect is conditioned by the quality of the exogenous signal. It is made worse where institutional features guarantee poor signal quality (that is, a bad policy is unlikely to be revealed). In this case, the probability of failure is higher from the start and quickly reaches unity. In the example, it begins at about 12 percent when citizens have antileader bias, and rapidly increases to certainty with the bias shifting in favor of the leader. In other words, under these conditions, citizens are quite unlikely to be able to impose any audience costs on the leader. If, on the other hand, the signal is of very high quality, the probability of failure is low and its increase with bias very limited. In the example, it starts

\footnotetext{
${ }^{21}$ The probability that a good policy generates a correct signal is constant and high because I assume that this would be the case regardless of regime type: all governments have incentives to make sure citizens learn about their successes, but governments who can control the media can suppress its ability to reveal their failures.
} 


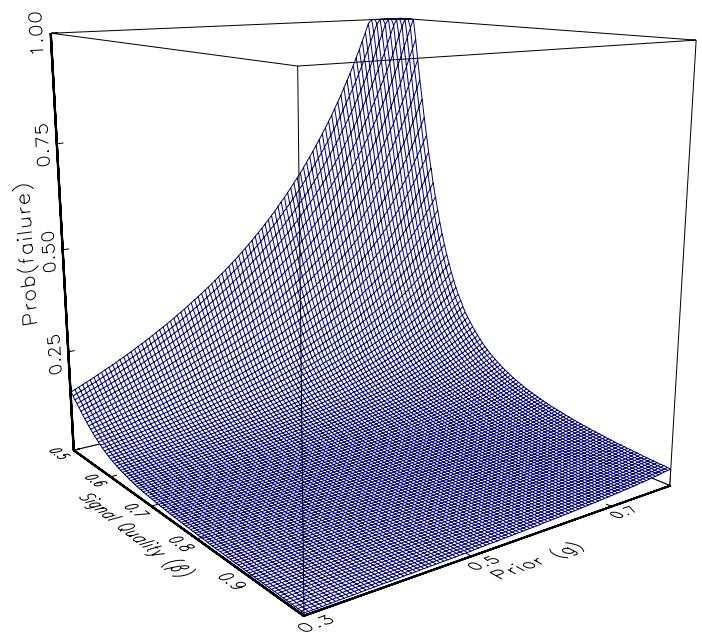

Figure 3: Impact of Signal Quality and Prior Bias on Policy Failure.

from close to 0 percent and goes up to about 5 percent even at the most extreme pro-leader bias. This suggests that:

HYPOTHESIS 4. The polity's ability to generate audience costs increases in the degree of media freedom from political interference.

The ceteris paribus clause in Hypothesis 1 is very important because authoritarian regimes and democracies may be able to generate weak audience costs through their independent signaling sources. It is important to emphasize that even though one normally does not associate autocracies with free media, the effect should still exist in regimes that are not fully repressive and that do guarantee at least some freedoms to journalists. As Geddes (1999) notes, not all authoritarian regimes are the same when it comes to their capacity for repression or control of informational outlets. One should not also neglect the fact that democracies may exercise a lot of control over dissemination of information during a crisis, as Adams (1986) has noted for the British Ministry of Defense during the Falklands War.

The information transmission mechanism in this model differs from Van Belle's (1997) theory that privileges democracies because of the legitimacy of news sources that is absent in authoritarian regimes. However, the findings in Van Belle (2000) are consistent with Hypothesis 4 . There is no research that I am aware of that tackles the question in authoritarian settings: this should provide a critical test that will distinguish between the two approaches.

The impact of signal quality is much more pronounced than that of prior bias. To see this, note the abrupt drop-off in probability of failure even at the high pro-leader bias of about 80 percent: it begins from certainty when the signal is bad and then plunges to 25 percent with a moderate increase in signal quality of less than 20 percent. To effect the corresponding drop holding the signal at a constant low quality, the bias has to shift against the leader by over 45 percent.

For democracies, this is in keeping with the finding that the president's "decisions on policy do not affect his popularity so much as their results" (Kernell 1978). In particular, the fate of democratic leaders would crucially depend on the chance revelation of some 
particularly favorable or damaging piece of information that is independently verifiable and therefore credible. Thus, democrats may be unwilling to repeal bad policies until forced by sudden and unexpected revelation of such information (e.g. the Pentagon Papers). Brody and Shapiro (1989) show how the news of the Iran-Contra Affair led to a sharp decline in President Reagan's popularity, contrary to the expectations of the "rally 'round the flag" theory (Mueller 1973). This suggests a more refined hypothesis:

HyPOTHESIS 5. Popular leaders in regimes with few media freedoms will be least able to generate audience costs, whereas unpopular leaders in regimes with guaranteed media freedoms will be most able to do so.

While prior bias is doubtless important, the "watchful eye" that produces the exogenous signal is crucial for the rate at which leaders risk continuing bad policies against the wishes of their citizenry. Thus, from the non-strategic informational perspective, citizens in a policy with media freedoms are far more likely to learn the qualities of the policies implemented by their government. This ability varies with the quality of the watchful eye, and can provide an imperfect sanctioning mechanism. ${ }^{22}$

We now examine the cost range that supports the fully revealing equilibrium. As already noted, it shrinks when citizens are biased for or against the incumbent relative to the opposition:

HYPOTHESIS 6. Audience costs are most likely to matter in closely contested polities, when citizens favor neither the incumbent nor the opposition too much.

This effect of bias in priors in the fully informative equilibrium is closely related to the one in Smith (1998, p. 629), who also finds that as bias increases in either direction, the probability of intervention (that reveals information) decreases. The logic is the same: when bias exists, the impact that new information will have on citizen behavior is comparatively weak, so there is less incentive to reveal such information and risking associated costs.

The cost range increases in $b$ : as policies become more important (good ones deliver more and bad ones cost more), full revelation becomes easier because the range of costs that would support it widens. This implies that

HYPOTHESIS 7. Audience costs are most likely to matter only for salient policies of great national importance.

This finding is intuitive and seems corroborated by empirical evidence (Aldrich, Sullivan and Borgida 1989). It is worth noting that, perhaps counter-intuitively, the cost range width is unrelated to the private benefits from holding office provided Assumption 2 is satisfied (they are sufficiently larger than public benefits). On the other hand, the interval is sensitive to the expected benefit from having a competent leader versus an incompetent one: the larger the difference in producing a good policy between the two types, the wider the range that can support full efficiency in equilibrium. The cost range increases in $p$ and decreases in $q$ for all $p>q$. Very high $p$ means that the competent leader is very likely to produce good policies, and very low $q$ means that the incompetent leader is very unlikely to do so.

\footnotetext{
${ }^{22}$ Empirically, there may be limits to how much citizens may be able to learn even from intensive coverage (Bennett 1994).
} 
When $p$ is close to $q$, the expected difference competence will make is too small to matter. Because the magnitude of expected swings in policy is what matters, this suggests that:

HYPOTHESIS 8. Audience costs are most likely to arise when there is a large expected swing in policy if the leader is replaced.

Tentative support for this hypothesis comes from Page and Brody (1972) who analyze the 1968 U.S. presidential elections. They find that Vietnam policy was very important to the voters-"only 7 per cent failed to express an opinion" and half of the people surveyed thought Vietnam was the most important problem the government had to solve. However, the authors found that voters were quite unable to tell the candidates apart on this crucial issue and traced this failure to the ambiguity in the candidates' campaign speeches. They conclude that "members of the public were entirely justified in seeing Nixon and Humphrey as standing close together near the center of the Vietnam policy scale, far from the extremes of immediate withdrawal or escalation for complete military victory" (p. 985). This implies that Nixon would not have been able to rely on audience costs to signal resolve, something that may help explain persistent North Vietnamese intransigence despite Linebacker I, and the need for the Christmas bombing: only a successful military campaign could persuade them to relent, at least for a couple of years.

\section{Conclusion}

Domestic audience costs play an increasingly important role in theoretical and empirical work in international relations. However, the theoretical mechanism that is supposed to generate these costs has not been thoroughly investigated. Instead, analyses assume that these audience costs exist and that they are linearly related to regime type (higher in democracies), and then proceed to build additional theoretical structure or conduct empirical tests. I have argued in this article, that there are several ways to approach the problem with microfoundations but they are not very satisfactory.

Domestic political audiences could help leaders commit credibly to a course of action by tying their hands. To do that, these audiences must be able to sanction the leader, and rational audiences would only sanction a leader who behaves contrary to their interests. It is not difficult to generate such "bad" behavior if the leader has policy preferences that are very different from the citizens. Consequently, I constructed a model where leaders would have least incentive to deviate from their responsibilities as agents of the people. In such an environment, office-holding motivations may induce distorting behavior by the incumbents, and this is precisely what citizens would wish to sanction. Ironically, the very existence of a sanctioning device to control leaders can produce perverse incentives for behavior it is designed to eliminate. Domestic audience costs constitute the reduction in probability of retaining office for pursuing policies contrary to the interests of one's constituency. Hence, generating such costs crucially depends on the citizens' ability to infer policy quality from information available to them.

I considered two potential sources of such information: politically-motivated strategic behavior of better-informed actors like the government and the opposition, and a non-political but potentially biased source, like the media. The results suggest that perfect audience costs can arise endogenously only in mixed regimes where the costs of repressing dissent are 
neither too high nor too low. The opposition's ability to credibly reveal private information is severely curtailed by its incentives to seek office. Only under limited circumstances can they commit to a fully revealing strategy, where the credibility of their commitment is induced by the partial repressive threat of the leader. More generally, however, the opposition's behavior degenerates either in universal endorsement of policies when the leader represses all dissent (autocracies), or endorsement babble when the leader never represses (democracies). Thus, the exogenous noisy signaling mechanism plays a more important role in disciplining leaders, who will condition their behavior on the chance that the citizens would learn quite a bit about policy quality anyway.

These findings show that while audience costs can arise endogenously given a strategic citizenry, (1) it is difficult to generate them, which implies that their impact may be very small empirically, and (2) the process depends on both institutional features and media freedoms that do not necessarily vary linearly in regime type, which implies that existing empirical tests may be flawed. Thus, the model provides a micro-foundation for domestic audience costs but also sounds a cautionary note about their use in applied research.

\section{A Proofs}

We now round up a herd of lemmas that significantly simplify equilibrium analysis by eliminating a large number of candidate strategy profiles.

LEMMA 1. In any sequential equilibrium, either $g_{4}=g_{5} \in\{0,1\}$ or else $0<g_{5}<g_{4}<$ 1; and either $g_{2}=g_{3} \in\{0,1\}$ or else $0<g_{3}<g_{2}<1$.

Proof. The only difference between $g_{4}$ and $g_{5}$ is induced by the different non-strategic probabilities associated with the two policy types. Let $\hat{g}$ denote the citizens' updated belief before observing the noisy signal. Given the information obtained from the signal, Bayes rule yields $g_{4}=\frac{\hat{g} \alpha}{\hat{g} \alpha+(1-\hat{g}(1-\beta)}$ and $g_{5}=\frac{\hat{g}(1-\alpha)}{\hat{g}(1-\alpha)+(1-\hat{g}) \beta}$. For $\hat{g} \in\{0,1\}$, it is readily seen that $g_{4}=g_{5}=\hat{g}$. For any $\hat{g} \in(0,1)$, it is easily verified that $0<g_{5}<\hat{g}<g_{4}<1$. Because this holds for any sequence of completely mixed strategies, it must hold in any sequential equilibrium. The proof for $g_{2}, g_{3}$ is analogous.

LEMMA 2. There is no sequential equilibrium in which the leader repeals the good policy and continues the bad one with positive probability.

Proof. Suppose the leader repeals the good policy and continues the bad one with positive probability in some equilibrium. Bayes rule pins down the posterior $g_{1}=1$. Given this posterior, repealing the bad policy would yield $V^{B}$. We now show that under no circumstances would the leader continue the bad policy. There are three potential strategy profile types to consider for expected payoffs when the policy is bad.

Case 1: the opposition dissents and the leader allows it. In this case the leader would get at most $V^{B}-b<V^{B}$, so continuation is not rational. Case 2: the opposition dissents and the leader represses it. In this case the leader would get at most $V^{B}-b-c<V^{B}$, so continuation is not rational. Case 3: the opposition endorses the policy. In this case the leader would get at most $V^{B}-b<V^{B}$, so continuation is not rational. 
LEMma 3. There is no sequential equilibrium in which the opposition dissents when the policy is bad and gets repressed.

Proof. Suppose it is optimal for the leader to repress when the policy is bad, and thus $-c+V^{B}-\beta\left(V^{B}+v\right)\left(1-\gamma_{6}\right) \geq \pi_{e}^{o}+\left(V^{B}-\pi_{e}^{o}\right)\left[(1-\beta) g_{4}+\beta g_{5}\right]$. Because the RHS is minimized at $g_{4}=g_{5}=0$, it follows that a necessary condition for the existence of this equilibrium is that $c \leq V^{B}-\pi_{e}^{o}-\beta\left(V^{B}+v\right)\left(1-\gamma_{6}\right) \equiv \bar{c}$. Suppose now that it also optimal for the opposition to dissent, and thus $\pi^{B}-(1-c)+\beta\left(V_{e}^{o}-\pi^{B}\right)\left(1-\gamma_{6}\right) \geq$ $V_{e}^{o}-\left(V_{e}^{o}-\pi^{B}\right)\left[(1-\beta) g_{2}+\beta g_{3}\right]$. Because the RHS is minimized at $g_{2}=g_{3}=1$, it follows that another necessary condition for the existence of this equilibrium is that $c \geq 1-\beta\left(V_{e}^{o}-\right.$ $\left.\pi^{B}\right)\left(1-\gamma_{6}\right) \equiv \underline{c}$. Thus, such an equilibrium requires $c \in[\underline{c}, \bar{c}]$. However, this interval does not exist. To see that $\underline{c}>\bar{c}$, note that $\underline{c}-\bar{c}=1-V^{B}+\pi_{e}^{o}+\beta\left(1-\gamma_{6}\right)\left(v+2 \pi^{B}-\pi_{e}^{o}\right)>0$, where the inequality follows from $1-V^{B}+\pi_{e}^{o}=1-v+\pi_{e}^{o}-\pi^{B}>0$ because $1>v$ and $\pi_{e}^{o}>\pi^{B}$, and from $v+\pi^{B}-\pi_{e}^{o}=v-b(p-q)\left(\mu_{e}^{o}-\mu^{B}\right)>0$ from Assumption 2. Thus, there can exist no value for $c$ that would satisfy both necessary conditions for this equilibrium. Consequently, such an equilibrium cannot exist.

Lemma 4. Suppose that the leader continues all policies. Then there is no sequential equilibrium in which the opposition plays a separating strategy.

Proof. Suppose first that the opposition dissents only when the policy is good, which implies $g_{2}=g_{3}=0$. Given these beliefs, the payoff from deviating to endorsing the good policy is $V_{e}^{o}$. The payoff from dissenting from the good policy and getting repressed is strictly smaller than $V_{e}^{o}-(1-c)<V_{e}^{o}$, so dissent cannot be optimal. If the leader does not repress this dissent, then Bayes rule pins down $g_{4}=g_{5}=1$, and the expected payoff from dissenting is $\pi^{G}<V_{e}^{o}$, and so dissent cannot be optimal in this case either.

Suppose now that the opposition dissents only when the policy is bad, which implies $g_{2}=g_{3}=1$. If the leader allows this dissent, Bayes rule pins down $g_{4}=g_{5}=0$. The leader could strictly improve the payoff by repealing the bad policy, which would yield at least $\pi_{e}^{o}>\pi_{e}^{o}-b$, which is what continuing it gets. Thus, in any such equilibrium the leader must be repressing dissent when the policy is bad. But Lemma 3 shows that no such equilibria exist.

LEMMA 5. Suppose that the leader continues all policies and the opposition always dissents. Then there is no sequential equilibrium in which the leader's plays a separating repression strategy.

Proof. If the leader represses only when the policy is good, Bayes rule pins down $g_{6}=1$. Endorsing the good policy yields at least $\pi^{G}>\pi^{G}-(1-c)$, which is what the opposition gets by dissenting. By Lemma 3 , the profile where the leader represses dissent when the policy is bad cannot be an equilibrium either.

Proof of Proposition 1. First, I derive the conditions that the following strategies as equilibrium. Next, I show that there are no other fully revealing equilibria. The claim is that if $c \in[\underline{c}, \bar{c}]$, then the following strategies and beliefs constitute a unique (up to specification of off-the-path beliefs) sequential equilibrium. Leader: when the policy is good, continue 
and repress dissent; when the policy is bad, repeal and do not repress dissent; in the second period, continue good policy and repeal bad policy. Opposition: support good policy and dissent from bad policy. Citizens: select according to (1) and the following updated beliefs: $g_{1}=0$, and $g_{2}=g_{3}=1$ along the equilibrium path; and $g_{4}=g_{5}=0, g_{6}=\underline{g}_{6}$ off the equilibrium path. Bayes rule pins down beliefs $g_{1}=0$, and $g_{2}=g_{3}=1$. Optimality of repressing when the policy is good implies that:

$$
-c+\alpha V^{G}+(1-\alpha)(-v)+\gamma_{6}(1-\alpha)\left(V^{G}+v\right) \geq \pi_{e}^{o}+\left(V^{G}-\pi_{e}^{o}\right)\left[\alpha g_{4}+(1-\alpha) g_{5}\right] .
$$

The necessary condition for this to hold, at $g_{4}=g_{5}=0$, is then $c \leq V^{G}-\pi_{e}^{o}-(1-$ $\left.\gamma_{6}\right)(1-\alpha)\left(V^{G}+v\right)$. This yields the upper bound on the costs at $\gamma_{6}=1$ :

$$
c \leq V^{G}-\pi_{e}^{o} \equiv \bar{c} .
$$

To obtain an expression that satisfies $\gamma_{6}=1$, we solve for $g_{6}$, which gives $1-m$. Thus, we have a bound for this belief: $\underline{g}_{6}=\max \{0,1-m\}$. Any $g_{6} \geq \underline{g}_{6}$ guarantees that $\gamma_{6}=1$. I now show that (7) also establishes an upper bound on the admissible off-the-path beliefs $g_{4}$ and $g_{5}$. Rewriting the expression for the necessary condition with $\gamma_{6}=1$ yields:

$$
\alpha g_{4}+(1-\alpha) g_{5} \leq 1-\frac{c}{V^{G}-\pi_{e}^{o}} \equiv \bar{g}<1
$$

By Lemma 1, this implies that $g_{4}, g_{5}<1$. Let $\bar{g}$ denote the largest belief that is necessary to render repression optimal. Optimality of allowing dissent when the policy is bad implies: $\pi_{e}^{o}+\left(V^{B}-\pi_{e}^{o}\right)\left[(1-\beta) g_{4}+\beta g_{5}\right] \geq-c+(1-\beta) V^{B}+\beta(-v)+\gamma_{6} \beta\left(V^{B}+v\right)$. We now have $g_{5} \leq g_{4} \Rightarrow(1-\beta) g_{4}+\beta g_{5} \leq \alpha g_{4}+(1-\alpha) g_{5} \leq \bar{g}$, where the first inequality is established by Lemma 1 , and the second follows from $\alpha, \beta>\frac{1}{2}$, and the last is from (9). Thus, given the maximal belief allowable in equilibrium by (9), optimality of dissent yields the necessary condition: $c \geq(1-\bar{g})\left(V^{B}-\pi_{e}^{o}\right)-\left(1-\gamma_{6}\right) \beta\left(V^{B}+v\right)$. We already know that $\bar{g}<1$, and that $\gamma_{6}$ must be sufficiently high, so we can rewrite this as a sufficient condition with $g_{4}=g_{5}=0$ and $\gamma_{6}=1$, or: $c \geq V^{B}-\pi_{e}^{o} \equiv \underline{c}$. When the policy is good, the opposition supports it and if it dissents, it will be repressed, and thus: $\pi^{G} \geq$ $\pi^{G}+\left(1-\gamma_{6}\right)(1-\alpha)\left(V_{e}^{o}-\pi^{G}\right)-(1-c)$. The necessary condition, at $\gamma_{6}=1$, is clearly satisfied. When the policy is bad, the opposition dissents and does not get repressed, and so: $V_{e}^{o}-\left(V_{e}^{o}-\pi^{B}\right)\left[(1-\beta) g_{4}+\beta g_{5}\right] \geq \pi^{B}$. This inequality holds strictly for all admissible $g_{4}, g_{5}$.

Continuing the good policy given that the opposition would support it yields an expected payoff of $V^{G}+b>\pi_{e}^{o}$, which is what the leader would obtain by deviating and repealing it. Therefore, this decision is optimal. Repealing the bad policy yields an expected payoff of $\pi_{e}^{o}$, while continuing it, given that the opposition would dissent without getting repressed, yields $-b+\pi_{e}^{o}+\left(V^{B}-\pi_{e}^{o}\right)\left[(1-\beta) g_{4}+\beta g_{5}\right]=\pi_{e}^{o}-b<\pi_{e}^{o}$, where we use the fact that since in equilibrium some beliefs $g_{4}, g_{5}$ prevent this deviation, then preventing it under $g_{4}=g_{5}=0$ will be sufficient. This establishes that these strategies do form a sequential equilibrium.

The next step is to demonstrate uniqueness. The above equilibrium is unique in its class in the sense that all sequential equilibria in this class have the same equilibrium path of 
play specified by the strategies. ${ }^{23}$ Showing that this equilibrium is the only informative one is more involved and requires the methodical elimination of all other possible strategy profiles.

I first show that there are no other equilibria in which the leader repeals the bad policy and continues the good one. Suppose the leader continues the good policy and repeals the bad one. In all such separating equilibria, Bayes rule pins down $g_{1}=0$.

Case 1: the opposition endorses all policies regardless of quality. These strategies imply $g_{2}=g_{3}=1$ by Bayes rule. By continuing the bad policy, the leader would obtain $V^{B}-b>$ $\pi_{e}^{o}$, which is what repealing it yields. Therefore, none of these profiles can be equilibria.

Case 2: the opposition dissents from good policy. Suppose first the leader represses this dissent. These strategies imply $g_{6}=1$ by Bayes rule. The opposition's expected payoff then is $\pi^{G}-(1-c)<\pi^{G}$, which is the least it would obtain by supporting the good policy instead. Thus, none of of these profiles can be equilibria.

Suppose now the leader allows this dissent. These strategies imply $g_{4}=g_{5}=1$ by Bayes rule. Allowing dissent when the policy is bad yields $V^{B}>V^{B}-c$, which is the most the leader could expect by repressing it. Therefore, in any such sequential equilibrium, the leader must allow dissent when the policy is bad. Suppose now that the opposition dissents from the bad policy. The leader could strictly improve the payoff by continuing the bad policy and getting $V^{B}-b>\pi_{e}^{o}$, which is what repeal yields. Therefore, in any such equilibrium, the opposition must endorse the bad policy. Suppose now the opposition endorses the bad policy. Because it dissents from the good policy, it follows that $\alpha g_{4}+$ $(1-\alpha) g_{5}=1 \leq \alpha g_{2}+(1-\alpha) g_{3}$, which implies that $g_{2}=g_{3}=1$. Continuing the bad policy then yields $V^{B}-b>\pi_{e}^{o}$, which is what the leader gets from repealing it. Therefore, this cannot be a sequential equilibrium either. Thus, none of the profiles with the leader allowing dissent can be equilibria. This exhausts all profiles with the opposition dissenting only from good policies.

Case 3: the opposition endorses only the good policy. These strategies imply $g_{2}=g_{3}=1$ by Bayes rule. Suppose the leader allows dissent when the policy is good. Deviation to dissent is profitable as long as it is not the case that $g_{4}=g_{5}=1$. Therefore, in any such equilibrium, it must be the case that $g_{4}=g_{5}=1$, which implies that the leader would always allow dissent when the policy is bad because this would yield $V^{B}>V^{B}-c$, which is the most what repression would yield. Given that dissent from bad policy would be allowed, the leader could improve the expected payoff by continuing the bad policy, which would yield $V^{B}-b>\pi_{e}^{o}$, which is what repeal gets. Thus, there are no equilibria where the leader allows dissent when the policy is good.

Suppose now the leader represses regardless of policy quality. To prove that this cannot be an equilibrium, we show that the optimality of dissent when when the policy is bad is incompatible with the optimality of repressing it. Suppose this profile is an equilibrium. Since it is optimal to dissent from a bad policy despite being repressed, it follows that

\footnotetext{
${ }^{23}$ That is, because of the latitude in specifying the beliefs $g_{4}, g_{5}$, and $g_{6}$ within the limits established by the argument, we can support an infinite number of these sequential equilibria. For example, any pair $g_{4}, g_{5}$ that satisfies (9) would work, including beliefs strictly greater than zero. Similarly, we do not need to use $g_{6}=\underline{g}_{6}$, and any $g_{6} \geq g_{6}$ would work just as fine in giving $\gamma_{6}=1$. However, these equilibria only differ in these off-the-path beliefs and the equilibrium path of play in all of them is the same, so our substantive predictions would remain the same. It is worth noting that these different beliefs imply shifts in the cost range as well.
} 
$-(1-c)+\pi^{B}+\left(1-\gamma_{6}\right) \beta\left(V_{e}^{o}-\pi^{B}\right) \geq \pi^{B}$, which implies that there exists an upper bound on permissible beliefs: $\gamma_{6} \leq 1-\frac{1-c}{\beta\left(V_{e}^{o}-\pi^{B}\right)} \equiv \bar{\gamma}$. Turning now to the leader's strategy under bad policy, optimality of repression implies: $-c+(1-\beta) V^{B}+\beta(-v)+\gamma_{6} \beta\left(V^{B}+v\right) \geq$ $\pi_{e}^{o}+\left(V^{B}-\pi_{e}^{o}\right)\left[(1-\beta) g_{4}+\beta g_{5}\right]$. In equilibrium, this decision is optimal for some beliefs $g_{4}, g_{5}$, and so it must be optimal under beliefs $g_{4}=g_{5}=0$, which simplifies the expression and establishes a lower bound on permissible beliefs: $\gamma_{6} \geq 1-\frac{V^{B}-\pi_{e}^{o}-c}{\beta\left(V^{B}+v\right)} \equiv \underline{\gamma}$. I now show that $\bar{\gamma}<\underline{\gamma}$, which implies that there exist no beliefs that can satisfy both optimality requirements. Note that $\bar{\gamma}<\underline{\gamma}$ reduces to $\frac{1-c}{V_{e}^{o}-\pi^{B}}>\frac{V^{B}-\pi_{e}^{o}-c}{V^{B}+v}$. From $v<1$, it follows that $V^{B}-\pi_{e}^{o}=v-b(p-q)\left(\mu_{e}^{o}-\mu^{B}\right)<1$, and therefore $1-c>V^{B}-\pi_{e}^{o}-c$. But $V^{B}+v-V_{e}^{o}+\pi^{B}=\pi^{B}+v-b(p-q)\left(\mu_{e}^{o}-\mu^{B}\right)>0$, where the inequality follows from Assumption 2. Thus, the numerator on the LHS is strictly greater than the numerator on the RHS, and the denominator on the LHS is strictly smaller than the denominator on the RHS, which establishes the inequality. Thus, the profile cannot be an equilibrium.

Therefore, all remaining sequential equilibria must involve policy failure. I now show that no remaining equilibria are fully revealing. Lemma 2 exhausts the possibilities for signaling at the repeal stage. Therefore, in any remaining fully revealing equilibrium, the leader must be continuing regardless of policy quality. Lemma 4 shows that there are no such equilibria with the opposition playing a separating strategy. Therefore, in any remaining fully revealing equilibrium, the opposition must be pooling on dissent. Lemma 5 shows that there are no such equilibria with the leader playing a separating repression strategy.

LEMma 6. There is no sequential equilibrium, in which the opposition dissents when the policy is good if the leader represses regardless of quality.

Proof. Suppose in some equilibrium it is optimal for the leader to repress when the policy is bad. This implies that $-c+V^{B}-\beta\left(V^{B}+v\right)\left(1-\gamma_{6}\right) \geq \pi_{e}^{o}+\left(V^{B}-\pi_{e}^{o}\right)\left[(1-\beta) g_{4}+\right.$ $\left.\beta g_{5}\right]$. Because the RHS is minimized at $g_{4}=g_{5}=0$, it follows that a necessary condition for the existence of this equilibrium is $c \leq V^{B}-\pi_{e}^{o}-\beta\left(V^{B}+v\right)\left(1-\gamma_{6}\right) \equiv \hat{c}$. Suppose that it is optimal for the opposition to dissent despite getting repressed when the policy is good. This implies $\pi^{G}+(1-\alpha)\left(V_{e}^{o}-\pi^{G}\right)\left(1-\gamma_{6}\right)-(1-c) \geq V_{e}^{o}-\left(V_{e}^{o}-\pi^{G}\right)\left[\alpha g_{2}+(1-\alpha) g_{3}\right]$. Because the RHS is minimized at $g_{2}=g_{3}=1$, it follows that a necessary condition for the optimality of this strategy is that $c \geq 1-(1-\alpha)\left(V_{e}^{o}-\pi^{G}\right)\left(1-\gamma_{6}\right) \equiv \hat{\hat{c}}$. Thus, a necessary condition for the existence of this equilibrium is that $c \in[\hat{\hat{c}}, \hat{c}]$. However, this interval does not exist. That is, $\hat{c}<\hat{\hat{c}}$ because $V^{B}-\pi_{e}^{o}-\beta\left(V^{B}+v\right)\left(1-\gamma_{6}\right)<1-(1-\alpha)\left(V_{e}^{o}-\pi^{G}\right)\left(1-\gamma_{6}\right)$. This inequality follows from $V^{B}-\pi_{e}^{o}=v+\pi^{B}-\pi_{e}^{o}<v<1$, and $\beta>1-\alpha$ with $V^{B}+v>V_{e}^{o}-\pi^{G}$, which imply that $\beta\left(V^{B}+v\right)\left(1-\gamma_{6}\right) \geq(1-\alpha)\left(V_{e}^{o}-\pi^{G}\right)\left(1-\gamma_{6}\right)$. Thus there can be no $c$ that would simultaneously satisfy both necessary conditions for the existence of this equilibrium.

Proof of Proposition 2. The argument in the text establishes the optimality of the pooling repressive strategy, while Lemmas 3 and 6 establish the optimality of the opposition's pooling endorsement strategy. By Corollary 1, the leader's strategy must also be pooling at the initial stage. I now establish the conditions necessary to support these two sequential equilibria given that $c \leq \underline{c}$. 
In the continuation (Type II) equilibrium, Bayes rule pins down the posterior beliefs $g_{2}=\frac{g \alpha}{g \alpha+(1-g)(1-\beta)}$ and $g_{3}=\frac{g(1-\alpha)}{g(1-\alpha)+(1-g) \beta}$. Assign the following off-the-path beliefs: $g_{1}=g_{4}=g_{5}=0$, and $g_{6}=1$. Optimality of continuing the good policy requires $b+\pi_{e}^{o}+\left(V^{G}-\pi_{e}^{o}\right)\left[\alpha g_{2}+(1-\alpha) g_{3}\right] \geq \pi_{e}^{o}+g_{1}\left(V^{G}-\pi_{e}^{o}\right)$, which, at $g_{1}=0$, is always satisfied regardless of beliefs $g_{2}, g_{3}$. Optimality of continuing the bad policy requires $-b+$ $\pi_{e}^{o}+\left(V^{B}-\pi_{e}^{o}\right)\left[(1-\beta) g_{2}+\beta g_{3}\right] \geq \pi_{e}^{o}+g_{1}\left(V^{B}-\pi_{e}^{o}\right)$, which, at $g_{1}=0$, yields the necessary condition:

$$
g>(1-\beta) g_{2}+\beta g_{3} \geq \frac{b}{V^{B}-\pi_{e}^{o}} .
$$

The first inequality follows from $g_{3}<g<g_{2}$, and $\beta>\frac{1}{2}$. Both $g_{2}$ and $g_{3}$ are strictly increasing in $g$. This implicitly defines a critical value for $g$. Let $g_{B}$ be that value. For all $g \geq g_{B}$, the condition is satisfied, and the Type II equilibrium exists.

In the repeal (Type I) equilibrium, Bayes rule pins down the posterior belief $g_{1}=g$. As before, we assign off the path beliefs as follows, $g_{2}=g_{3}=g_{4}=g_{5}=0$, and $g_{6}=1$. Optimality of repealing the bad policy requires the necessary condition, at $g_{2}=g_{3}=0$, of $-b \leq g\left(V^{B}-\pi_{e}^{o}\right)$, which is always satisfied. Optimality of repealing the good policy requires the necessary condition:

$$
g \geq \frac{b}{V^{G}-\pi_{e}^{o}}
$$

which implicitly defines a critical value for $g$. Let $g_{A}$ be that value. For any $g \geq g_{A}$, the conditions are satisfied and the Type I equilibrium exists. This establishes the first claim in the proposition.

Because $V^{G}-\pi_{e}^{o}>V^{B}-\pi_{e}^{o}$, it follows that the RHS in (10) is strictly larger than the RHS in (11). That is, the Type II equilibrium bound is larger than the Type I equilibrium bound. Whenever $g$ satisfies (10), it will necessarily satisfy (11), although the converse is not true. Thus, $g \geq g_{B} \Rightarrow g>g_{A}$. Thus, if $g \geq g_{B}$, then both Type I and Type II equilibria can be supported. If, however $g \in\left[g_{A}, g_{B}\right]$, then only Type I equilibrium can exist. (If $g<g_{A}$, then only partially revealing equilibria exist.) Consider now the Type I equilibrium and suppose the leader could deviate and continue the good policy if that would convince the citizens of its quality, and so, given the opposition's strategy, citizens would update $g_{2}=g_{3}=1$. This would give the leader a payoff of $V^{G}+b>\pi_{e}^{o}+g\left(V^{G}-\pi_{e}^{o}\right)$, which is what the equilibrium payoff is. If the leader continues the bad policy given these beliefs, the expected payoff is $V^{B}-b<\pi_{e}^{o}+g\left(V^{B}-\pi_{e}^{o}\right)$ for sufficiently high $g$. In other words, when $g$ is sufficiently high, the leader cannot benefit from continuing the bad policy even if re-election is certain. Thus, repealing the good policy is equilibrium-dominated, and the Intuitive Criterion (Cho and Kreps 1987) rules out the Type I equilibrium in this region, leaving only the Type II equilibrium.

Proof of Proposition 3. By Corollary 1, if the opposition plays a separating strategy, the leader must be pooling on repeal. Two such equilibria exist, but they are unintuitive. The leader can always improve the payoff by continuing the good policy if that would convince the citizens of its quality. Because the opposition plays a separating strategy, the information sets that are reached by continuing the good policy are different from the 
ones that are reached by continuing the bad policy, and so the leader cannot benefit from continuing the bad policy even under the new beliefs. This leaves four sequential equilibria, two for each failure type, distinguished by whether the opposition pools on endorsement or dissent. Deriving the conditions is analogous to the proof of Proposition 2.

\section{References}

Adams, Valerie. 1986. The Media and the Falklands Campaign. London: Macmillan.

Aldrich, John H., John L. Sullivan, and Eugene Borgida. 1989. "Foreign Affairs and Issue Voting: Do Presidential Candidates 'Waltz Before a Blind Audience?'." American Political Science Review 83 (March): 123-141.

Alesina, Alberto, John Londregan, and Howard Rosenthal. 1993. "A Model of the Political Economy of the United States." American Political Science Review 87 (March): 12-33.

Baum, Matthew. 2004. "Going Private: Public Opinion, Presidential Rhetoric, and the Domestic Politics of Audience Costs in U.S. Foreign Policy Crises." Journal of Conflict Resolution 48 (October): 603-631.

Bennett, Stephen Earl. 1994. “The Persian Gulf War's Impact on Americans' Political Information." Political Behavior 16 (June): 179-201.

Besley, Timothy, and Stephen Coate. 1998. "Sources of Inefficiency in a Representative Democracy: A Dynamic Analysis." The American Economic Review 88 (March): 139156.

Brody, Richard A., and Catherine R. Shapiro. 1989. "Policy Failure and Public Support: The Iran-Contra Affair and Public Assessment of President Reagan." Political Behavior 11 (December): 353-369.

Bueno de Mesquita, Bruce, James Morrow, Randolph Siverson, and Alastair Smith. 2003. The Logic of Political Survival. Cambridge: The M.I.T. Press.

Burns, Jimmy. 1987. The Land That Lost Its Heroes: How Argentina Lost the Falklands War. London: Bloomsbury.

Cho, In-Koo, and David M. Kreps. 1987. "Signaling Games and Stable Equilibria." Quarterly Journal of Economics 102 (May): 179-221.

Dorussen, Han, and Jongryn Mo. 2001. "Ending Economic Sanctions: Audience Costs and RentSeeking as Commitment Strategies." Journal of Conflict Resolution 45 (August): 395-426.

Downs, George W., and David M. Rocke. 1995. Optimal Imperfection? Domestic Uncertainty and Institutions in International Relations. Princeton: Princeton University Press.

Dur, Robert A.J. 2001. "Why do policy makers stick to inefficient decisions?" Public Choice 107 (June): 221-234. 
Eisinga, Rob, Philip Hans Franses, and Dick J.C. van Dijk. 1998. Timing of Vote Decision in First and Second Order Dutch Elections, 1978-1995. In Political Analysis, ed. Walter R. Mebane Jr. Ann Arbor: University of Michigan Press pp. 117-142.

Eyerman, Joe, and Robert A. Hart, Jr. 1996. "An Empirical Test of the Audience Cost Proposition: Democracy Speaks Louder than Words." Journal of Conflict Resolution 40 (December): 597-616.

Fearon, James D. 1994a. "Domestic Political Audiences and the Escalation of International Disputes." American Political Science Review 88 (September): 577-92.

Fearon, James D. 1994b. "Signaling versus the Balance of Power and Interests: An Empirical Test of a Crisis Bargaining Model.” Journal of Conflict Resolution 38 (June): 236-69.

Ferejohn, John. 1986. “Incumbent Performance and Electoral Control.” Public Choice 50 (1-3): 5-25.

Fiorina, Morris. 1981. Retrospective Voting in American National Elections. New Haven: Yale University Press.

Gaubatz, Kurt Taylor. 1996. "Democratic States and Commitment in International Relations." International Organization 50 (1): 109-139.

Geddes, Barbara. 1999. "Authoritarian Breakdown: Empirical Test of a Game Theoretic Argument." Presentated at the annual meeting of the American Political Science Association, Atlanta, September, 1999.

Goemans, Hein E. 2000. War and Punishment: The Causes of War Termination and the First World War. Princeton: Princeton University Press.

Gowa, Joanne. 2001. "Who Yields? Democracies in International Crises." Presented at the International Relations Speaker Series, Yale University, April 25, 2001.

Kernell, Samuel. 1978. "Explaining Presidential Popularity." American Political Science Review 72 (June): 506-522.

Knopf, Jeffrey W. 1998. "How Rational is "The Rational Public"? Evidence from U.S. Public Opinion on Military Spending." Journal of Conflict Resolution 42 (October): 544571.

Laffont, Jean-Jacques, and David Martimort. 2002. The Theory of Incentives: The Principal-Agent Model. Princeton: Princeton University Press.

Leeds, Brett Ashley. 1999. "Domestic Political Institutions, Credible Commitments, and International Cooperation." American Journal of Political Science 43 (October): 9791002.

Lipson, Charles. 2003. Reliable Partners: How Democracies Have Made a Separate Peace. Princeton: Princeton University Press. 
Lohmann, Susanne. 2003. "Why Do Institutions Matter? An Audience-Cost Theory of Institutional Commitment." Governance 16 (January): 95-110.

Macho-Stadler, Inés, and David Pérez-Castrillo. 1997. An Introduction to the Economics of Information. Oxford: Oxford University Press.

Mansfield, Edward, Helen Milner, and B. Peter Rosendorff. 2002. "Why Democracies Cooperate More: Electoral Control and International Trade Agreements." International Organization 56 (Summer): 477-513.

Miller, Arhtur H., and Martin P. Wattenberg. 1985. "Throwing the Rascals Out: Policy Performance Evaluations of Presidential Candidates, 1952-1980." American Political Science Review 79 (June): 359-372.

Miller, Joanne M., and Jon A. Krosnick. 2000. "News Media Impact on the Ingredients of Presidential Evaluations: Politically Knowledgeable Citizens are Guided by a Trusted Source." American Journal of Political Science 44 (April): 301-315.

Mueller, John E. 1973. War, Presidents, and Public Opinion. New York: John Wiley.

Page, Benjamin I., and Richard A. Brody. 1972. "Policy Voting and the Electoral Process: The Vietnam War Issue.” American Political Science Review 66 (September): 979-995.

Palmer, Glenn, and Peter J. Partell. 1999. "Audience Costs and Interstate Crises: An Empirical Assessment of Fearon's Model of Dispute Outcomes.” International Studies Quarterly 43 (June): 389-405.

Pion-Berlin, David. 1985. “The Fall of Military Rule in Argentina: 1976-1983.” Journal of Interamerican Studies and World Affairs 27 (Summer): 55-76.

Ramsay, Kristopher W. 2004. "Politics at the Water's Edge: Crisis Bargaining and Electoral Competition.” Journal of Conflict Resolution 48 (August): 459-486.

Richards, Diana, T. Clifton Morgan, Rick K. Wilson, Valerie L. Schwebach, and Gary D. Young. 1993. "Good Times, Bad Times, and the Diversionary Use of Force: A Tale of Some Not-So-Free Agents." Journal of Conflict Resolution 37 (3): 504-535.

Rogoff, Kenneth. 1990. "Equilibrium Political Budget Cycles." The American Economic Review 80 (March): 21-36.

Sartori, Anne E. 2002. "The Might of the Pen: A Reputational Theory of Communication in International Disputes." International Organization 56 (February): 121-149.

Schelling, Thomas C. 1966. Arms and Influence. New Haven: Yale University Press.

Schultz, Kenneth A. 1998. "Domestic Opposition and Signaling in International Crises." American Political Science Review 92 (December): 829-44. 
Schultz, Kenneth A. 1999. "Do Democratic Institutions Constrain or Inform? Contrasting Two Institutional Perspectives on Democracy and War." International Organization 53 (Spring): 233-266.

Schultz, Kenneth A. 2001a. Democracy and Coercive Diplomacy. Cambridge: Cambridge University Press.

Schultz, Kenneth A. 2001b. "Looking for Audience Costs." The Journal of Conflict Resolution 45 (February): 32-60.

Schultz, Kenneth A., and Barry R. Weingast. 2003. "The Democratic Advantage: Institutional Foundations of Financial Power in International Competition.” International Organization 57 (Winter): 1-40.

Shapiro, Robert Y., and Benjamin I. Page. 1988. "Foreign Policy and the Rational Public." Journal of Conflict Resolution 32 (June): 211-247.

Smith, Alastair. 1996a. "Diversionary Foreign Policy in Democratic Systems." International Studies Quarterly 40 (March): 133-153.

Smith, Alastair. 1996b. "Endogenous Election Timing in Majoritarian Parliamentary Systems." Economics and Politics 8 (July): 85-110.

Smith, Alastair. 1998. "International Crises and Domestic Politics." American Political Science Review 92 (3): 623-38.

Van Belle, Douglas. 1997. "Press Freedom and the Democratic Peace." Journal of Peace Research 40 (November): 405-414.

Van Belle, Douglas. 2000. Press Freedom and Global Politics. Westport: Praeger. 